\title{
STRUCTURAL BEHAVIOUR OF ELLIPTICAL HOLLOW SECTIONS UNDER COMBINED COMPRESSION AND UNIAXIAL BENDING
}

\author{
L. Gardner ${ }^{1, *}$, T.M. Chan ${ }^{2}$ and J.M. Abela ${ }^{1}$ \\ ${ }^{1}$ Department of Civil and Environmental Engineering, Imperial College London, \\ London, SW7 2AZ, United Kingdom \\ ${ }^{2}$ School of Engineering, University of Warwick, Coventry, CV4 7AL, United Kingdom \\ *(Corresponding author: E-mail: leroy.gardner@imperial.ac.uk)
}

\begin{abstract}
The structural behaviour of elliptical hollow sections (EHS) has been examined in previous studies under the isolated loading conditions of pure compression and pure bending. This paper examines the response of EHS under combined compression plus uniaxial bending at the cross-sectional level. Structural performance data were initially generated through a series of laboratory stub column tests with various load eccentricities. The measured geometric and material properties of the test specimens, together with the full load-deformation histories have been reported herein. The test data were supplemented by further results generated through parallel numerical studies. Slenderness parameters and limits for EHS under combined compression plus bending were developed following analytical work. Finally, the experimental and numerical data were used to verify proposed interaction expressions for the design of EHS under combined loading; these have been developed in accordance with Eurocode 3 for ease of future incorporation.
\end{abstract}

Keywords: Combined bending and axial compression, Eccentric compression, Elliptical hollow sections, Experiments, Interaction, Oval hollow sections, Steel structures, Testing

\section{INTRODUCTION}

Owing to their aesthetic appeal and sound structural efficiency, hot-finished elliptical hollow sections (EHS) have been adopted in a number of recent projects including the Honda Central Sculpture in Goodwood, UK, the Society Bridge in Braemar, UK (Corus [1]) and the airports at Barajas in Madrid, Spain (Viñuela-Rueda and Martinez-Salcedo [2]) and Heathrow in London, UK. The authors of the present paper have previously conducted extensive laboratory testing, supported by parallel numerical modelling studies, to examine the behaviour of elliptical hollow sections in compression (Chan and Gardner [3]) and bending (Chan and Gardner [4]). On the basis of the findings, slenderness parameters and slenderness limits for the cross-section classification of EHS have been proposed (Gardner and Chan [5]). Further recent studies on the elastic buckling of elliptical hollow sections (Zhu and Wilkinson [6], Ruiz-Terán and Gardner [7], and Silvestre [8]), the response of filled elliptical tubes (Roufegarinejad and Bradford [9], Zhao et al. [10], Yang et al. [11] and Zhao and Packer [12]) and the behaviour of connections to EHS (Bortolotti et al. [13], Choo et al. [14], Pietrapertosa and Jaspart [15] and Willibald et al. [16]) have also been performed. However, there currently remains a lack of verified design guidance for other structural phenomena. Development of such guidance is underway, and this paper focuses on the scenario for combined bending and axial force at cross-section level. Detailed experimental studies are described herein and design recommendations for resistance to combined bending and axial force are presented. 


\section{EXPERIMENTAL STUDY}

\section{$2.1 \quad$ Introduction}

A series of tensile material tests, compressive stub column tests and eccentric compression tests have been carried out to investigate the structural behaviour of hot-finished elliptical hollow sections. All tests were performed in the Structures Laboratory of the School of Engineering, University of Warwick. A total of four tensile coupons, four stub columns under uniform compression and eight stub columns under eccentric compression were tested. Two section sizes were employed - EHS $150 \times 75 \times 5$ and EHS $150 \times 75 \times 6.3$ - both having a cross-sectional aspect ratio of two. All tested material was hot-finished carbon steel, grade S355 supplied by Corus Tubes [17]. This section summarises the testing apparatus, the experimental procedures and the test results obtained.

\section{$2.2 \quad$ Tensile Coupon Tests}

Tensile coupon tests were performed to establish the basic material stress-strain response; this was subsequently utilised during the analysis of the test results and in the development of numerical models. The tests were carried out in accordance with EN 10002-1 (CEN) [18]. Parallel coupons were machined longitudinally from the two flattest portions of the cross-sections (i.e. the regions of maximum local radius of curvature). Two coupon tests, designated TC1 and TC2, were performed for each section size. The key results from the four coupon tests are summarised in Table 1.

Table 1. Mean Measured Dimensions and Key Results from Tensile Coupon Tests

\begin{tabular}{cccccc}
\hline Tensile coupons & $\begin{array}{c}\text { Width } \\
b_{t c}(\mathrm{~mm})\end{array}$ & $\begin{array}{c}\text { Thickness } \\
t(\mathrm{~mm})\end{array}$ & $\begin{array}{c}\text { Young's } \\
\text { modulus } \\
E\left(\mathrm{~N} / \mathrm{mm}^{2}\right)\end{array}$ & $\begin{array}{c}\text { Yield stress } \\
f_{y}\left(\mathrm{~N} / \mathrm{mm}^{2}\right)\end{array}$ & $\begin{array}{c}\text { Ultimate } \\
\text { tensile stress } \\
f_{u}\left(\mathrm{~N} / \mathrm{mm}^{2}\right)\end{array}$ \\
\hline $150 \times 75 \times 5.0-\mathrm{TC} 1$ & 19.85 & 4.61 & 211800 & 377 & 501 \\
$150 \times 75 \times 5.0-\mathrm{TC} 2$ & 19.85 & 4.63 & 213000 & 365 & 506 \\
$150 \times 75 \times 6.3-\mathrm{TC} 1$ & 19.84 & 6.47 & 216300 & 410 & 529 \\
$150 \times 75 \times 6.3-\mathrm{TC} 2$ & 19.83 & 6.38 & 216600 & 408 & 529 \\
\hline
\end{tabular}

\section{$2.3 \quad$ Stub Column Tests}

Four stub columns were tested in pure axial compression to assess load carrying capacity and deformation capacity. Full load-end shortening curves were recorded, including the post-ultimate range. The nominal lengths of the stub columns were chosen such that they were sufficiently short not to fail by overall buckling, yet still long enough to contain a representative residual stress pattern. The stub column lengths were taken as two times the larger cross-sectional dimension. The stub column test arrangement is shown in Figure 1. The end platens of the testing arrangement were flat and parallel. Four linear variable displacement transducers (LVDTs) were used to determine the end shortening of the stub columns between the end platens of the testing machine. Four linear electrical resistance strain gauges were affixed to each specimen at mid-height, and at the ends of the major and minor axes. The strain gauges were initially used for alignment purposes, and later to modify the end shortening data from the LVDTs to eliminate the elastic deformation of the end platens. Load, strain, displacement and input voltage were all recorded using the data acquisition equipment ORION. 
Measurements of major and minor axis diameters ( $2 a$ and $2 b$, respectively), material thickness $t$ and stub column length $L$ were taken. The mean measured dimensions and maximum geometric local imperfections $\omega_{0}$ of the test specimens for the four stub column specimens are presented in Table 2; cross-section geometry and notation is defined in Figure 2. The cross-sectional area for the EHS stub columns is defined using the exact formulae adopted by the authors in previous studies (Chan and Gardner [3]). Two stub column tests, designated SC1 and SC2, were performed for each section size.

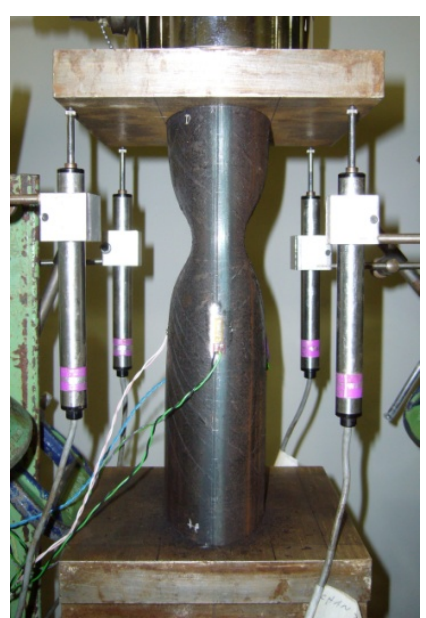

Figure 1. Stub Column Tests

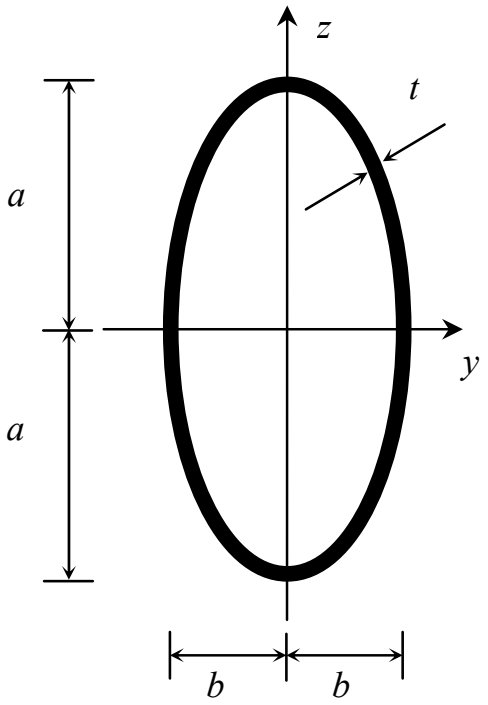

Figure 2. Geometry of an Elliptical Hollow Section

Table 2. Mean Measured Dimensions and Key Results from Stub Column Tests

\begin{tabular}{ccccccc}
\hline $\begin{array}{c}\text { Stub column } \\
\text { designation }\end{array}$ & $\begin{array}{c}\text { Larger } \\
\text { outer } \\
\text { diameter } \\
2 a(\mathrm{~mm})\end{array}$ & $\begin{array}{c}\text { Smaller } \\
\text { outer } \\
\text { diameter } \\
2 b(\mathrm{~mm})\end{array}$ & $\begin{array}{c}\text { Thickness } \\
t(\mathrm{~mm})\end{array}$ & $\begin{array}{c}\text { Length } \\
L(\mathrm{~mm})\end{array}$ & $\begin{array}{c}\text { Measured } \\
\text { maximum local } \\
\text { imperfection } \\
\omega_{0}(\mathrm{~mm})\end{array}$ & $\begin{array}{c}\text { Ultimate } \\
\text { load } \\
N_{u}(\mathrm{kN})\end{array}$ \\
\hline $150 \times 75 \times 5.0-\mathrm{SC} 1$ & 150.25 & 75.80 & 4.85 & 300.00 & 0.099 & 671 \\
$150 \times 75 \times 5.0-\mathrm{SC} 2$ & 150.05 & 76.00 & 4.90 & 300.05 & 0.072 & 676 \\
$150 \times 75 \times 6.3-\mathrm{SC} 1$ & 148.15 & 76.05 & 6.72 & 300.15 & 0.078 & 973 \\
$150 \times 75 \times 6.3-\mathrm{SC} 2$ & 148.85 & 76.05 & 6.64 & 300.15 & 0.036 & 990 \\
\hline
\end{tabular}

Compression tests on stub columns reveal the average compressive response of the cross-sections. Ultimate failure is due to local buckling of the cross-section. For cross-sections comprising slender elements, local buckling may occur in the elastic range. For more stocky cross-sections, local buckling may occur following significant inelastic deformation. Measured end shortening readings from the LVDTs were modified on the basis of the strain gauge readings to account for the elastic deformation of the end platens (that are present in the LVDT measurements) using a similar method to that employed by Rasmussen [19] and Gardner and Nethercot [20]. A summary of the key test results including ultimate test load $N_{u}$ is also given in Table 2. The results of the stub column tests are analysed and discussed in the following section.

\subsection{Unixial Bending and Compression Tests}

The primary aim of the eccentric compression tests was to investigate the cross-section response of EHS under combined bending and axial compression. The load was introduced through hardened steel knife-edges fixed to the ends of the specimens. The load eccentricity was varied to provide a range of proportions of axial load to bending, with the resulting $N_{u} / N_{c, R d}$, where $N_{c, R d}$ is the cross-section compression resistance, ranging between 0.26 and 0.76 . The nominal eccentricities about the minor axis were $25 \mathrm{~mm}$ and $75 \mathrm{~mm}$ whilst the nominal eccentricities about the major axis 
were $25 \mathrm{~mm}$ and $100 \mathrm{~mm}$. The nominal column lengths were $300 \mathrm{~mm}$. The general testing configuration is depicted in Figure 3. The loading, $N$ was applied through the knife-edge at an eccentricity, $e$ to the centroidal axis of the specimen, resulting in a uniform moment $(=\mathrm{Ne})$ along the column length, prior to lateral deformation - see Figure 4a. The loading was recorded by a $1000 \mathrm{kN}$ load cell located at the top end of the columns. Vertical displacement was measured at the loaded end of the columns by two LVDTs, whilst two inclinometers were positioned at each end of the columns to measure end rotation. As discussed by Fujimoto et al. [21], the deformation of the specimens generates a further second order moment $M_{2}=N \delta$, where $\delta$ is the lateral deflection, and the maximum moment at the mid-height is equal to $M_{1+2}=N \times\left(e+\delta_{\text {mid }}\right)-$ see Figure $4 \mathrm{~b}$. An additional LVDT was located at the mid-height of the columns to measure the lateral deflection. Eight linear electrical resistance strain gauges were affixed to the section to measure the longitudinal strain distribution around the section at mid-height. The strain gauge at the extreme fibre, near the lateral LVDT, was offset by $5 \mathrm{~mm}$ to avoid contact with the lateral LVDT. Load, strain, displacement and input voltage were all recorded using the data acquisition equipment ORION.

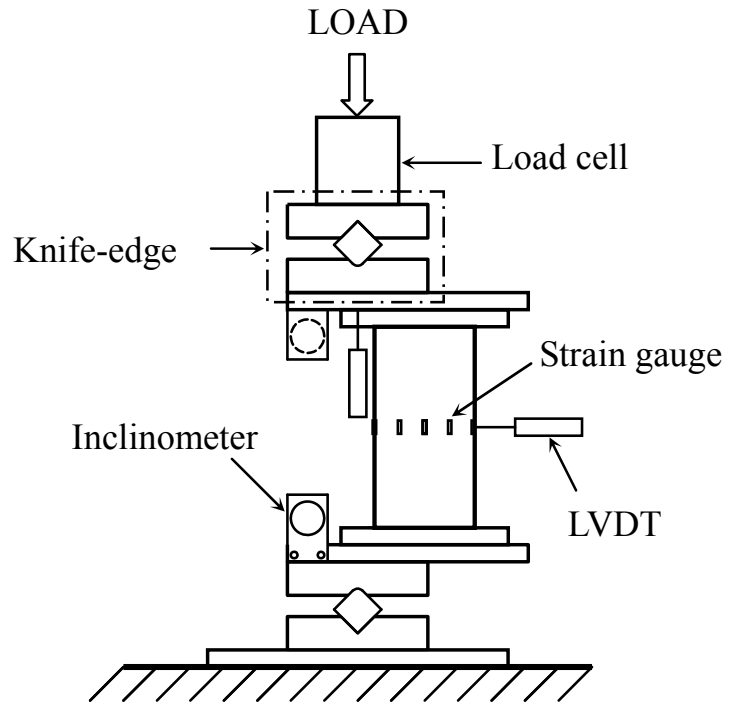

(a) Schematic view

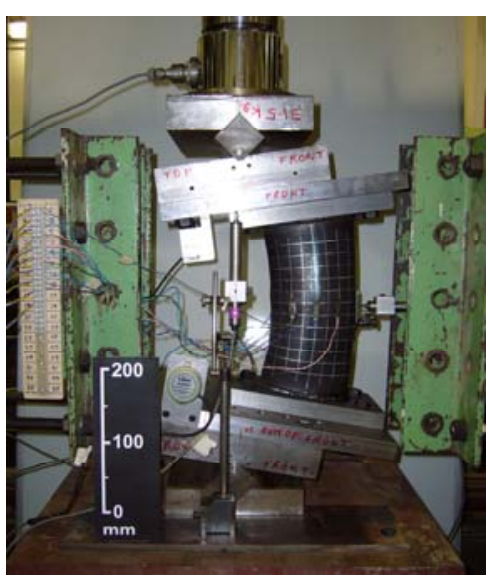

(b) Experimental setup

Figure 3. Eccentric Compression Test Arrangement

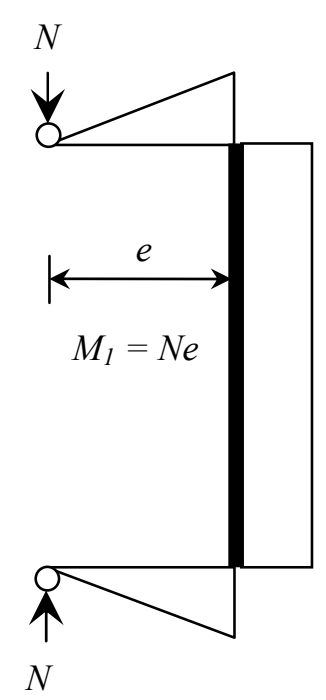

(a) Undeformed specimen

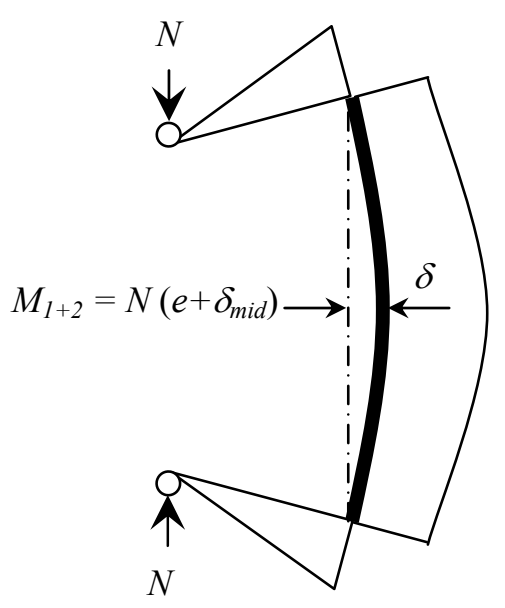

(b) Deformed specimen

Figure 4. Bending Moment due to Eccentric Compression 
The mean measured dimensions and maximum local geometric imperfections $\omega_{0}$ are presented in Table 3. Geometric properties including cross-sectional area and section moduli for the EHS specimens are defined using the exact formulae adopted by the authors in previous studies (Chan and Gardner [3, 4]). The test specimens were labelled such that the nominal section size, type of test, eccentricity axis and eccentricity value can be easily identified. For example, for specimen $150 \times 75 \times 5.0$-MI- 25 , the " $150 \times 75 \times 5.0$ " designates "nominal major diameter $\times$ nominal minor diameter $\times$ nominal thickness"; "MI" indicates an applied eccentric moment about the minor axis; "MA" indicates an applied eccentric moment about the major axis and "25" signifies an eccentricity of $25 \mathrm{~mm}$. The key results from the uniaxial bending and compression tests have been reported in Tables 3 and 4 .

Table 3. Mean Measured Dimension and Key Results from the Minor Axis Uniaxial Bending and Compression Tests

\begin{tabular}{|c|c|c|c|c|c|c|c|}
\hline Specimens & $\begin{array}{l}\text { Larger } \\
\text { outer } \\
\text { diameter } \\
2 a(\mathrm{~mm})\end{array}$ & $\begin{array}{l}\text { Smaller } \\
\text { outer } \\
\text { diameter } \\
2 b(\mathrm{~mm})\end{array}$ & $\begin{array}{c}\text { Thickness } \\
t(\mathrm{~mm})\end{array}$ & $\begin{array}{l}\text { Length } \\
L(\mathrm{~mm})\end{array}$ & $\begin{array}{c}\text { Measured } \\
\text { maximum } \\
\text { local imp. } \\
\omega_{0}(\mathrm{~mm})\end{array}$ & $\begin{array}{c}\text { Ultimate } \\
\text { load } \\
N_{u}(\mathrm{kN})\end{array}$ & $\begin{array}{c}\text { Bending } \\
\text { moment } \\
\text { at } N_{u} \text {, } \\
M_{1+2} \\
(\mathrm{kNm})\end{array}$ \\
\hline $150 \times 75 \times 5.0-\mathrm{MI}-25$ & 150.00 & 76.15 & 4.81 & 300.05 & 0.068 & 343 & 10.6 \\
\hline $150 \times 75 \times 5.0-\mathrm{MI}-75$ & 150.20 & 75.90 & 4.88 & 300.00 & 0.080 & 181 & 14.4 \\
\hline $150 \times 75 \times 6.3-\mathrm{MI}-25$ & 148.70 & 76.00 & 6.65 & 300.10 & 0.073 & 500 & 13.6 \\
\hline $150 \times 75 \times 6.3-\mathrm{MI}-75$ & 149.55 & 75.80 & 6.80 & 300.10 & 0.277 & 248 & 19.7 \\
\hline
\end{tabular}

Table 4. Mean Measured Dimension and Key Results from the Major Axis Uniaxial Bending and Compression Tests

\begin{tabular}{|c|c|c|c|c|c|c|c|}
\hline Specimens & $\begin{array}{c}\text { Larger } \\
\text { outer } \\
\text { diameter } \\
2 a(\mathrm{~mm})\end{array}$ & $\begin{array}{l}\text { Smaller } \\
\text { outer } \\
\text { diameter } \\
2 b(\mathrm{~mm})\end{array}$ & $\begin{array}{c}\text { Thickness } \\
t(\mathrm{~mm})\end{array}$ & $\begin{array}{l}\text { Length } \\
L(\mathrm{~mm})\end{array}$ & $\begin{array}{c}\text { Measured } \\
\text { maximum } \\
\text { local imp. } \\
\omega_{0}(\mathrm{~mm})\end{array}$ & $\begin{array}{c}\text { Ultimate } \\
\text { load } \\
N_{u}(\mathrm{kN})\end{array}$ & $\begin{array}{c}\text { Bending } \\
\text { moment } \\
\text { at } N_{u}, \\
M_{1+2} \\
(\mathrm{kNm})\end{array}$ \\
\hline $150 \times 75 \times 5.0-\mathrm{MA}-25$ & 150.50 & 75.65 & 4.94 & 300.05 & 0.129 & 490 & 18.5 \\
\hline $150 \times 75 \times 5.0-\mathrm{MA}-100$ & 150.20 & 76.95 & 4.84 & 299.95 & 0.099 & 235 & 27.4 \\
\hline $150 \times 75 \times 6.3-\mathrm{MA}-25$ & 148.40 & 76.10 & 6.72 & 300.10 & 0.060 & 712 & 30.0 \\
\hline $150 \times 75 \times 6.3-\mathrm{MA}-100$ & 148.55 & 76.00 & 6.74 & 300.10 & 0.138 & 342 & 42.4 \\
\hline
\end{tabular}

\section{NUMERICAL SIMULATIONS}

Numerical modelling of the behaviour of elliptical hollow sections subjected to uniaxial bending and compression was undertaken in parallel with the experimental programme. This was performed using the nonlinear finite element (FE) package ABAQUS [22]. The aims of this investigation were initially to replicate the experimental results and validate the numerical models and subsequently to perform parametric studies to generate further structural performance data. Four-noded reduced integration shell elements with six degrees of freedom per node were used in the FE models. These are designated as S4R in the ABAQUS element library, and are suitable for thin or think shell applications [22]. A uniform mesh density of $2 a / 10(a / b) \times 2 a / 10(a / b) \mathrm{mm}$ with an upper bound of $20 \times 20 \mathrm{~mm}$ was employed. Simple support conditions were simulated by restraining suitable degrees of freedom at the ends of the members. 
The tests were modelled using the measured dimensions of the test specimens and measured material stress-strain data. The form of geometric imperfections was taken to be the lowest elastic eigenmode pattern, an example of which is shown in Figure 5.

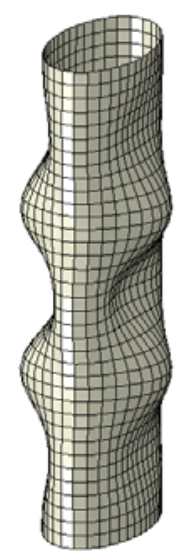

Figure 5. Lowest Elastic Buckling Mode Shape (Eigenmode) for EHS 150×75×5.0-MA-25

The imperfection amplitude $\omega_{0}$ was considered as two fixed fractions of the material thickness $t$ $(t / 10$ and $t / 100)$ in addition to the measured imperfection values. Residual stresses were not included in the models. The true material stress-strain relationships were generated from the engineering stress-strain curves obtained from the tensile coupon tests, and material nonlinearity was incorporated into the numerical models by means of a piecewise linear stress-strain model in order to replicate the strain-hardening region. The modified Riks method [22] was used to solve the geometrically and materially nonlinear models, which enabled the post-ultimate behaviour to be traced. Results from the numerical simulations are tabulated in Table 5, in which, the ratios between the FE ultimate loads (FE $N_{u}$ ) and the experimental ultimate loads (Test $N_{u}$ ) are shown and compared for the different imperfection levels. The overall mean and coefficient of variation (COV) of FE $N_{u} /$ Test $N_{u}$ are also reported.

With the measured imperfections, the mean FE $N_{u} /$ Test $N_{u}$ is 0.99 with a coefficient of variation of $7 \%$. The sensitivity to imperfections may be seen to be generally relatively low with, on average, an $8 \%$ drop in capacity arising from an increase in imperfection amplitude from $t / 100$ to $t / 10$. The sections that are loaded with an eccentricity to the major axis show the greatest variation in response to variation in imperfection amplitude, with larger imperfections limiting progression into the strain hardening regime.

Comparisons between the test and the FE results, in terms of applied moment $M(=N e)$ versus end rotation $\phi$, based on the measured imperfection amplitudes $\omega_{0}$ are shown in Figure 6.

Replication of the tests results was found to be satisfactory with the numerical models able to successfully capture the observed stiffness, ultimate load, overall load-end shortening response and failure patterns. Having verified the general ability of the FE models to replicate the test behaviour, a series of parametric studies was conducted. The primary aim of the parametric studies was to generate additional structural performance data for further load eccentricities and to investigate the influence of cross-section slenderness on the ultimate load-bearing capacity. A piecewise linear material stress-strain model derived from the tensile coupon tests conducted on the $150 \times 75 \times 6.3$ sections was employed throughout the parametric studies and is shown in Figure 7. Initial local geometric imperfections took the form of the lowest elastic eigenvalue with an amplitude of $\omega_{0}=$ $t / 100$, which was close to the measured value and provided the best agreement with the test results, as shown in Table 5 and as found in previous studies [3]. 
Table 5. Comparison of Uniaxial Bending and Compression Test Results with FE Results for Varying Imperfection Amplitude

\begin{tabular}{lccc}
\hline \multirow{2}{*}{ Specimens } & \multicolumn{3}{c}{ FE $N_{u} /$ Test $N_{u}$} \\
\cline { 2 - 4 } & $\omega_{0}=t / 10$ & $\omega_{0}=t / 100$ & Measured $\omega_{0}$ \\
\hline $150 \times 75 \times 5.0-\mathrm{MI}-25$ & 0.97 & 1.01 & 1.01 \\
$150 \times 75 \times 5.0-\mathrm{MI}-75$ & 0.87 & 0.90 & 0.90 \\
$150 \times 75 \times 6.3-\mathrm{MI}-25$ & 1.03 & 1.05 & 1.05 \\
$150 \times 75 \times 6.3-\mathrm{MI}-75$ & 0.91 & 0.93 & 0.93 \\
$150 \times 75 \times 5.0-\mathrm{MA}-25$ & 0.89 & 0.99 & 0.93 \\
$150 \times 75 \times 5.0-\mathrm{MA}-100$ & 0.88 & 1.02 & 0.99 \\
$150 \times 75 \times 6.3-\mathrm{MA}-25$ & 0.92 & 1.09 & 1.09 \\
$150 \times 75 \times 6.3-\mathrm{MA}-100$ & 0.94 & 1.06 & 1.05 \\
Mean & 0.93 & 1.01 & 0.99 \\
COV & 0.06 & 0.07 & 0.07 \\
\hline
\end{tabular}

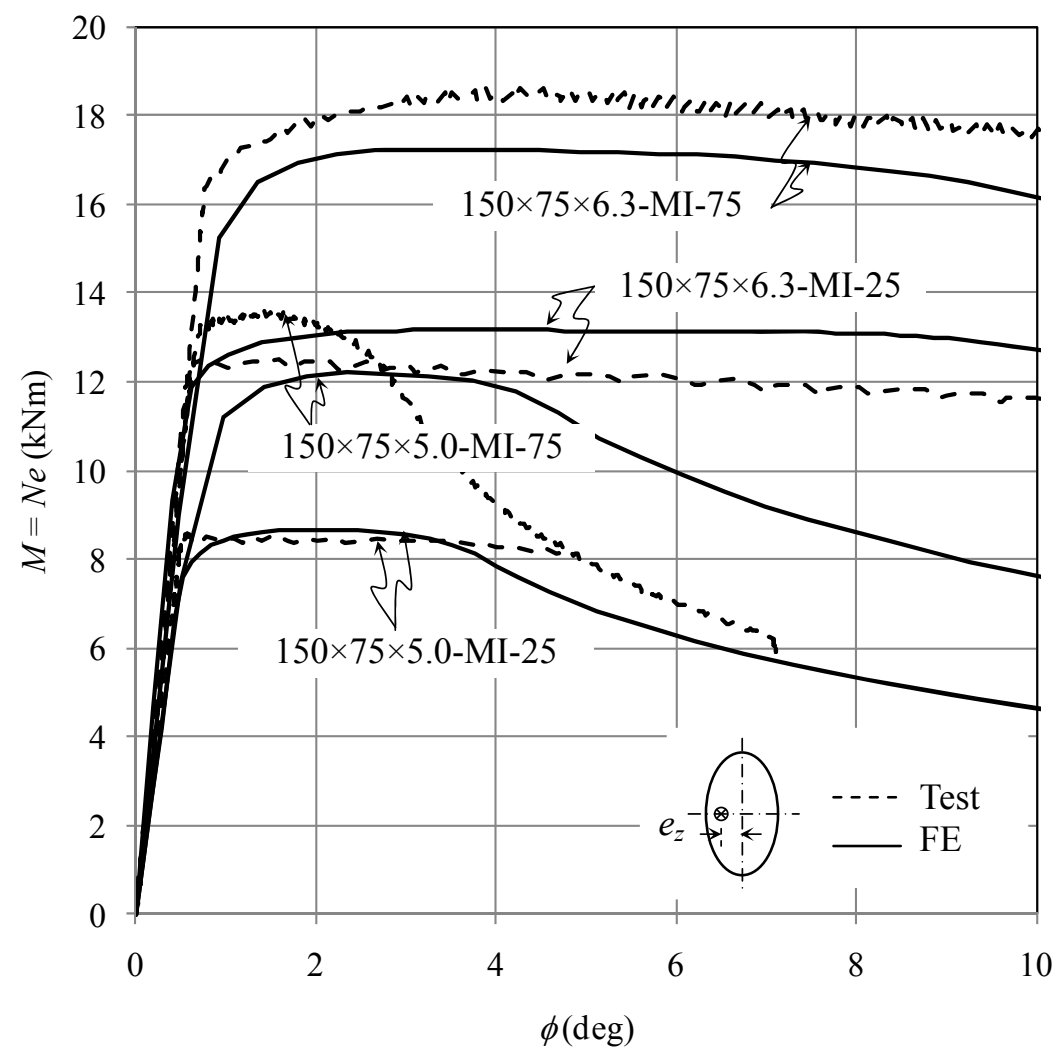

(a) Eccentricity to minor axis 


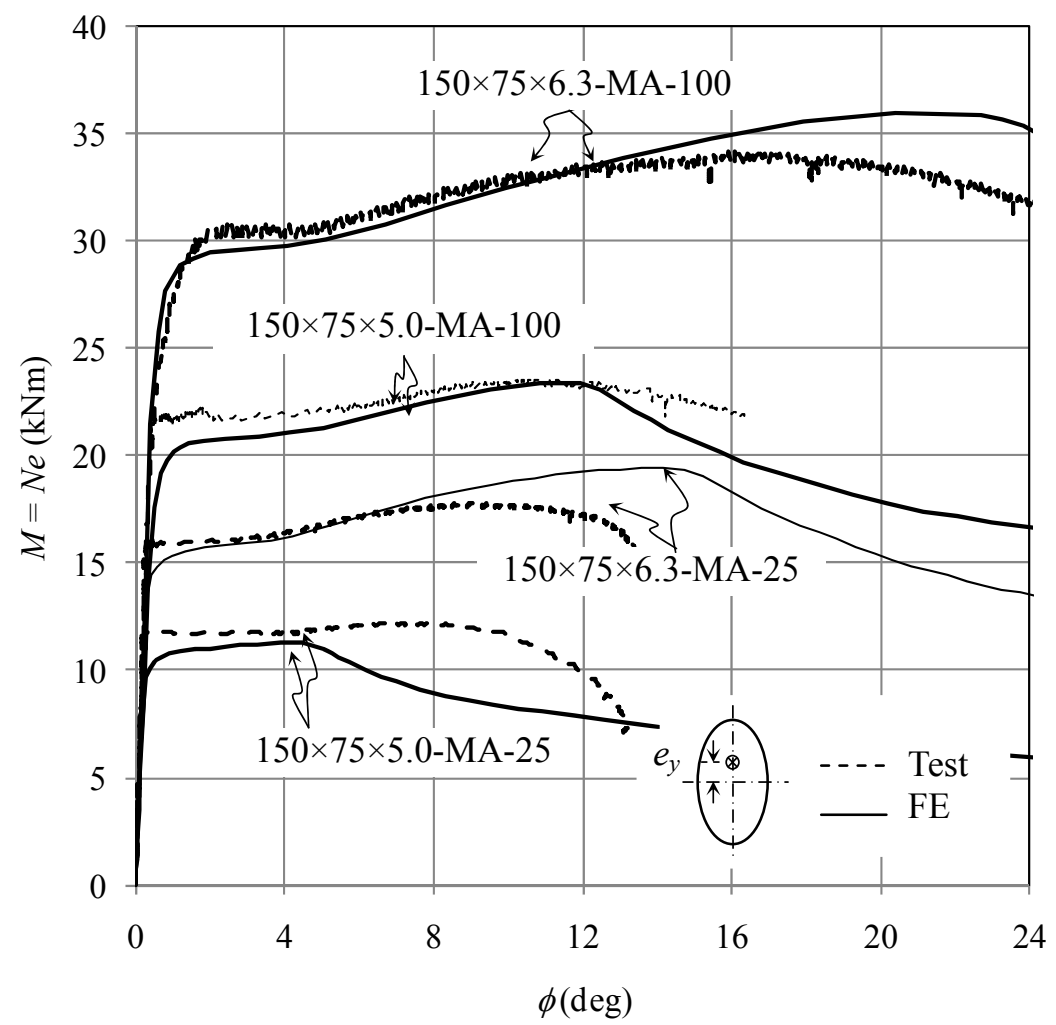

(b) Eccentricity to major axis

Figure 6. Moment Versus Rotation Curves

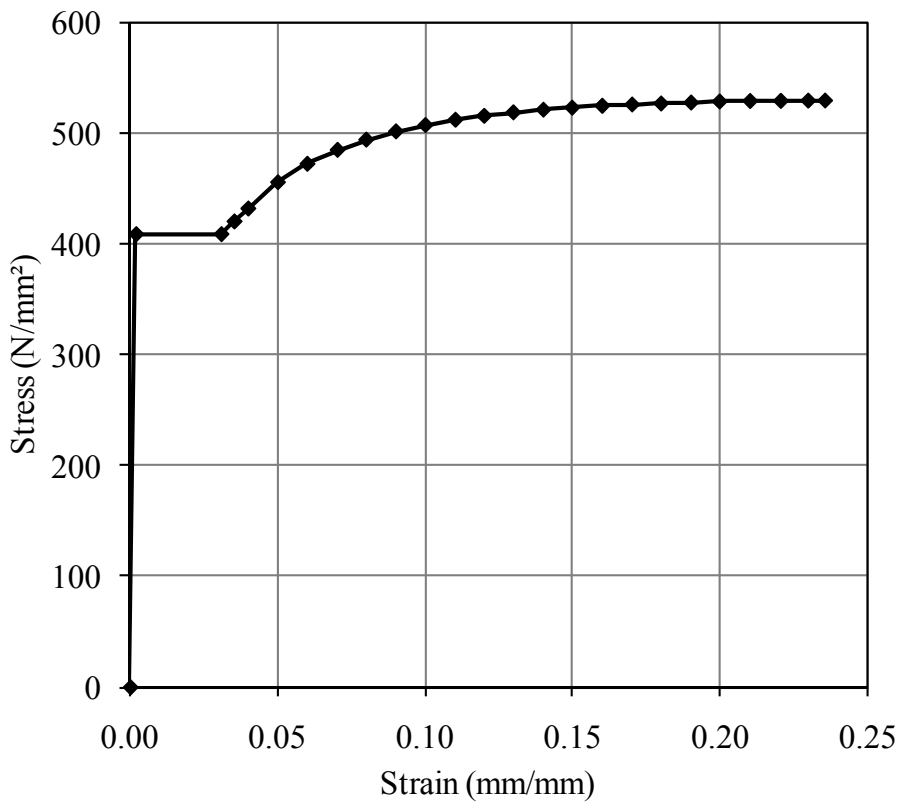

Figure 7. Piecewise Linear Stress-strain Model

The section sizes considered in the parametric studies were $150 \times 75$ and $150 \times 150$ (to generate comparative CHS data) with varying thicknesses to cover a spectrum of cross-section slenderness. The eccentricities considered to the minor axis $\left(e_{z}\right)$ were $10 \mathrm{~mm}, 25 \mathrm{~mm}$ and $75 \mathrm{~mm}$ and to the major axis $\left(e_{y}\right)$ were $1 \mathrm{~mm}, 10 \mathrm{~mm}, 25 \mathrm{~mm}$ and $100 \mathrm{~mm}$. The results are examined in the following section, where they have been utilised for the validation of proposed slenderness parameters and cross-section classification limits for elliptical hollow sections under combined loading. 


\section{SLENDERNESS PARAMETERS UNDER COMBINED LOADING}

\subsection{Introduction}

Cross-section classification of EHS under the individual loading scenarios of pure compression and pure bending has been previously studied by Chan and Gardner [3], [4], Gardner and Chan [5], Ruiz-Terán and Gardner [7] and Zhao and Packer [12]. The aim of this section is to obtain suitable slenderness parameters for EHS under combined compression and uniaxial bending.

Tables 6 and 7 summarise the bounds of this investigation by presenting the slenderness parameters and cross-section classification limits for CHS and EHS in pure compression and pure bending respectively. In these tables, and for the subsequent analyses, $D$ is the diameter of the CHS, $D_{e}$ is the equivalent diameter of the EHS (with $D_{e, c}$ and $D_{e, b}$ being the equivalent diameters for EHS under pure compression and pure bending, respectively), $\varepsilon^{2}=235 / f_{y}$ to allow for a range of yield strengths and $t$ is the cross-section thickness. The slenderness limits presented in BS 5950-1 [23], ANSI/AISC 360-05 [24], AISC [25] and AS 4100 [26] have been converted to their equivalent value with respect to the EN 1993-1-1 [27] slenderness measure, with $E=210000 \mathrm{~N} / \mathrm{mm}^{2}$, for ease of comparison.

The concept of the equivalent diameter, $D_{e}$, stems from extensive analytical work on the elastic buckling of oval hollow sections (OHS) and EHS under pure axial compression conducted by Kempner [28] and Hutchinson [29]. Kempner [28] concluded that the elastic buckling stress of an OHS could be accurately predicted from the classical elastic buckling formula for a circular hollow section (CHS) but with a radius $\left(r_{c r}=D_{e} / 2\right)$ equal to the maximum local radius of curvature of the OHS and that the solution was a lower bound. Hutchinson [29] extended this application of the equivalent diameter to EHS. Table 6 summarises the cross-section slenderness parameters for CHS given in current international codes, as well as the proposed slenderness parameters for EHS published in recent literature.

Table 6. Summary of Slenderness Parameters and Cross-section Classification Limits for Pure Compression for CHS and EHS

\begin{tabular}{|c|c|c|c|c|c|}
\hline & \multirow[t]{2}{*}{ Reference } & \multirow{2}{*}{$\begin{array}{l}\text { Cross-section slenderness } \\
\text { parameter }\end{array}$} & \multicolumn{3}{|c|}{$\begin{array}{l}\text { Equivalent EN 1993-1-1 [27] } \\
\text { slenderness limits }\end{array}$} \\
\hline & & & Class 1 & Class 2 & Class 3 \\
\hline \multirow{4}{*}{ 焉 } & EN 1993-1-1 [27] & $\frac{D}{t} \frac{f_{y}}{235}$ & 50.0 & 70.0 & 90.0 \\
\hline & BS 5950-1 [23] & $\frac{D}{t} \frac{f_{y}}{275}$ & - & - & 93.6 \\
\hline & $\begin{array}{l}\text { ANSI/AISC 360-05 } \\
{[24] \text { and AISC [25] }}\end{array}$ & $\frac{D}{t} \frac{f_{y}}{E}$ & - & - & 98.3 \\
\hline & AS 4100 [26] & $\frac{D}{t} \frac{f_{y}}{250}$ & - & - & 87.2 \\
\hline & $\begin{array}{l}\text { Chan and Gardner [3] } \\
\text { and SCI/BSCA [31] }\end{array}$ & $\frac{D_{e, c}}{t} \frac{f_{y}}{235} ; D_{e, c}=\frac{2 a^{2}}{b}$ & - & - & 90.0 \\
\hline$\underset{\sim}{\mathscr{I}}$ & $\begin{array}{c}\text { Ruiz-Terán and } \\
\text { Gardner [7] }\end{array}$ & $\begin{array}{c}\frac{D_{e, c}}{t} \frac{f_{y}}{235} ; D_{e, c}=2 a\left(1+f\left(\frac{a}{b}-1\right)\right), \\
f=1-2.3\left(\frac{t}{2 a}\right)^{0.6}\end{array}$ & - & - & 90.0 \\
\hline
\end{tabular}


Local buckling of EHS in minor $(z-z)$ axis bending is similar to that in pure axial compression since buckling initiates at the same point i.e. that of greatest radius of curvature (Chan and Gardner [4]). In the case of bending about the major $(y-y)$ axis, local buckling initiates, in general, neither at the point of maximum radius of curvature nor at the extreme compressive fibre, since the former now lies on the neutral axis and the latter is where the section is of greatest stiffness (i.e. minimum local radius of curvature). The point of initiation of elastic local buckling of an EHS in major axis bending can be theoretically located at a critical radius of curvature $r_{c r}$. This is found by identifying the maximum value of the function $r \sigma$ which is the product of the varying radius of curvature of an EHS and an elastic bending stress distribution (Gerard and Becker [30]). The critical radius for major axis bending was found by Gerard and Becker [30] to be $r_{c r}=0.65 a^{2} / b$. For the purposes of defining a slenderness parameter for cross-section classification of an EHS in major axis bending, the critical radius was later modified to $0.4 a^{2} / b$ (i.e. $D_{e}=0.8 a^{2} / b$ ) by Chan and Gardner [4] on the basis of experimental findings, noting that the capacity of structural steel sections is not only influenced by elastic buckling, but may also involve post-buckling and an interaction with material yielding. The analytical work of Gerard and Becker [30] is extended in Section 4.3 of this paper to identify $r_{c r}$ under combined axial load and major axis bending.

Table 7 presents a comparison of cross-section slenderness parameters and limits for CHS in pure bending given in current codes of practice, as well as the corresponding items proposed for EHS.

Table 7. Summary of Slenderness Parameters and Cross-section Classification Limits for Pure Bending for CHS and EHS

\begin{tabular}{|c|c|c|c|c|c|}
\hline & \multirow{2}{*}{ Reference } & \multirow{2}{*}{$\begin{array}{l}\text { Cross-section slenderness } \\
\text { parameter }\end{array}$} & \multicolumn{3}{|c|}{$\begin{array}{c}\text { Equivalent EN 1993-1-1 [27] } \\
\text { slenderness limits }\end{array}$} \\
\hline & & & Class 1 & Class 2 & Class 3 \\
\hline \multirow{4}{*}{ 兄 } & EN 1993-1-1 [27] & $\frac{D}{t} \frac{f_{y}}{235}$ & 50.0 & 70.0 & 90.0 \\
\hline & BS 5950-1 [23] & $\frac{D}{t} \frac{f_{y}}{275}$ & 46.8 & 58.5 & 163.8 \\
\hline & $\begin{array}{l}\text { ANSI/AISC 360-05 [24] } \\
\text { and AISC [25] }\end{array}$ & $\frac{D}{t} \frac{f_{y}}{E}$ & 62.6 & - & 277.0 \\
\hline & AS 4100 [26] & $\frac{D}{t} \frac{f_{y}}{250}$ & 53.2 & - & 127.7 \\
\hline 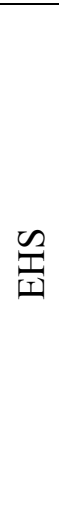 & Chan and Gardner [4] & $\begin{array}{c}\frac{D_{e, b}}{t} \frac{f_{y}}{235} \\
\text { where for pure minor axis bending: } \\
\qquad D_{e, b}=\frac{2.0 a^{2}}{b} \\
\text { and for pure major axis bending: } \\
D_{e, b}=\frac{0.8 a^{2}}{b} \text { for } \frac{a}{b}>1.357 \\
D_{e, b}=\frac{2.0 b^{2}}{a} \text { for } \frac{a}{b} \leq 1.357\end{array}$ & 50.0 & 70.0 & 140.0 \\
\hline
\end{tabular}




\subsection{Slenderness Parameter of EHS under Compression and Minor Axis Bending}

For both pure compression and pure minor axis bending, the point of initiation of local buckling coincides with the maximum radius of curvature in the section $\left(r_{\max }=a^{2} / b\right)$, as shown in Figure 8; hence Chan and Gardner [4] proposed that the equivalent diameter $D_{e}$ be taken as $2 a^{2} / b$ for these cases, with the corresponding slenderness parameter being $D_{e} / t \varepsilon^{2}=2 a^{2} / b t \varepsilon^{2}$. The equivalent diameter for EHS in pure compression was refined by Ruiz-Terán and Gardner [7] - see Table 6 to achieve more accurate results over a range of section thicknesses and aspect ratios.

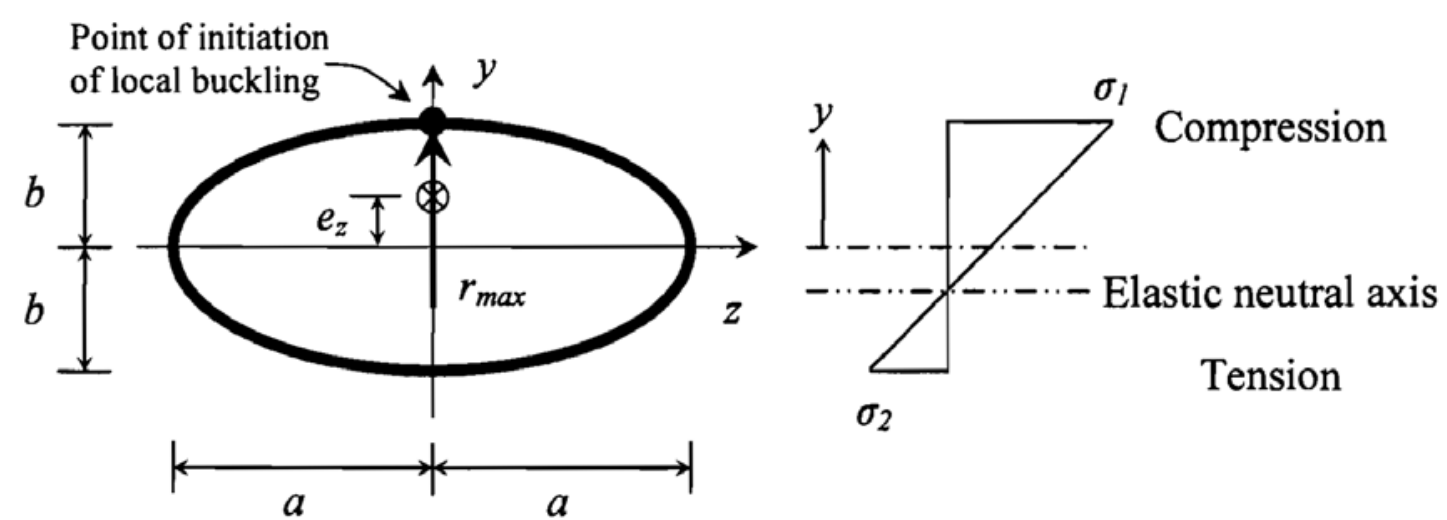

Figure 8. EHS under Combined Compression and Minor Axis Bending

For the case of an EHS under combined compression and minor axis bending, local buckling will clearly initiate at the same point as under compression or minor axis bending in isolation (i.e. the point of maximum radius of curvature); the equivalent diameter may therefore be given by Eq. 1 .

$D_{e, m i}=\frac{2 a^{2}}{b}$

\subsection{Slenderness Parameter of EHS under Compression and Major Axis Bending}

Under combined compression and major axis bending, the critical radius of curvature (i.e. the point of initiation of local buckling) will shift towards the centroidal axis as the compressive part of the loading increases. This shift can be derived as follows.

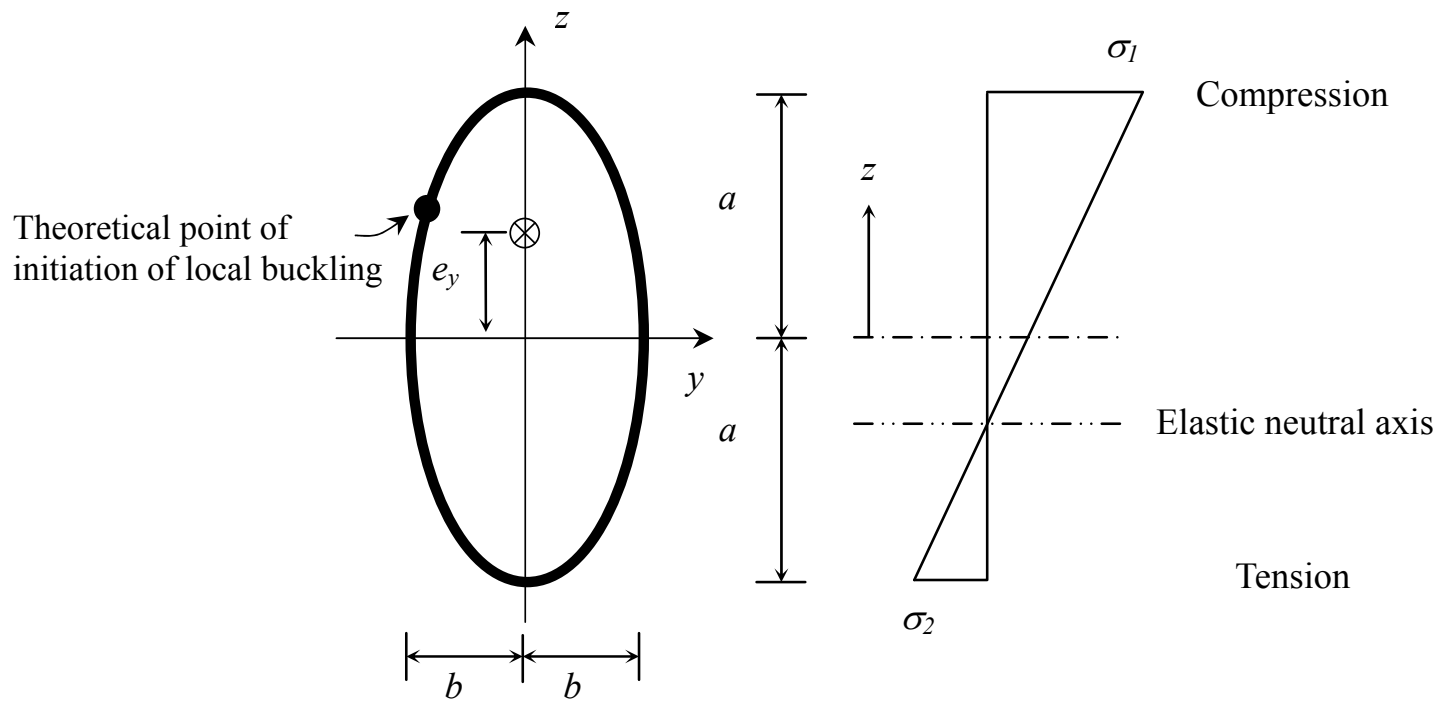

Figure 9. EHS under Combined Compression and Major Axis Bending 
From the general expression of the radius of curvature of an EHS and with reference to Figure 9, we have:

$$
r=\frac{a^{2}}{b}\left\{1-\left[1-\left(\frac{b}{a}\right)^{2}\right]\left(\frac{z}{a}\right)^{2}\right\}^{\frac{3}{2}}
$$

Assuming an elastic combination of compression plus bending, the stress at any location in the cross-section may be obtained from:

$$
\sigma=\frac{\sigma_{1}}{2 a}(\psi(a-z)+a+z)
$$

The location of the initiation of local buckling relative to the centroid of the section $z_{c r} / a$ occurs when the product $r \sigma$ (i.e. the product of Eqs. 2 and 3) is maximised. This yields:

$$
\frac{z_{c r}}{a}=\frac{1}{8(1-\psi)}\left(\sqrt{\left(9+\frac{16}{1-\frac{b^{2}}{a^{2}}}\right)\left(\psi^{2}+1\right)+2 \psi\left(9-\frac{16}{1-\frac{b^{2}}{a^{2}}}\right)}-3 \psi-3\right)
$$

where $\psi$ is the ratio of the end stresses given by:

$\psi=\frac{\sigma_{2}}{\sigma_{1}}$ and $-1 \leq \psi \leq 1$

The factor $\psi$, discussed further in Section 5, varies between 1 and -1 , with $\psi=1$ corresponding to pure compression and $\psi=-1$ corresponding to pure bending. Eq. 4 is plotted in Figure 10 for EHS with various $a / b$ ratios. From this figure it may be seen that for $\psi=1$, buckling initiates at $z / a=0$ (i.e. the point of maximum radius of curvature) for all aspect ratios. The position of initiation of buckling migrates up the section where the greater stresses exist as $\psi$ decreases. This migration is more rapid in sections of low aspect ratio where there is less variation in radius of curvature around the section.

The corresponding radius of curvature $r_{c r}$ (found by substituting $z=z_{c r}$ into Eq. 2), with the associated equivalent diameter $D_{e, m a}$ being two times this value:

$$
D_{e, m a}=\frac{2 a^{2}}{b}\left\{1-\left[1-\left(\frac{b}{a}\right)^{2}\right]\left(\frac{z_{c r}}{a}\right)^{2}\right\}^{\frac{3}{2}}
$$

Substituting Eq. 4 into Eq. 6, and assuming an aspect ratio $a / b=2$ yields the following direct relationship between $D_{e, m a}$ and $\psi$.

$$
D_{e, m a}=4 a\left(1-\frac{3}{256(1-\psi)^{2}}\left(\frac{1}{3} \sqrt{273 \psi^{2}+273-222 \psi}-3 \psi-3\right)^{2}\right)^{\frac{3}{2}}
$$




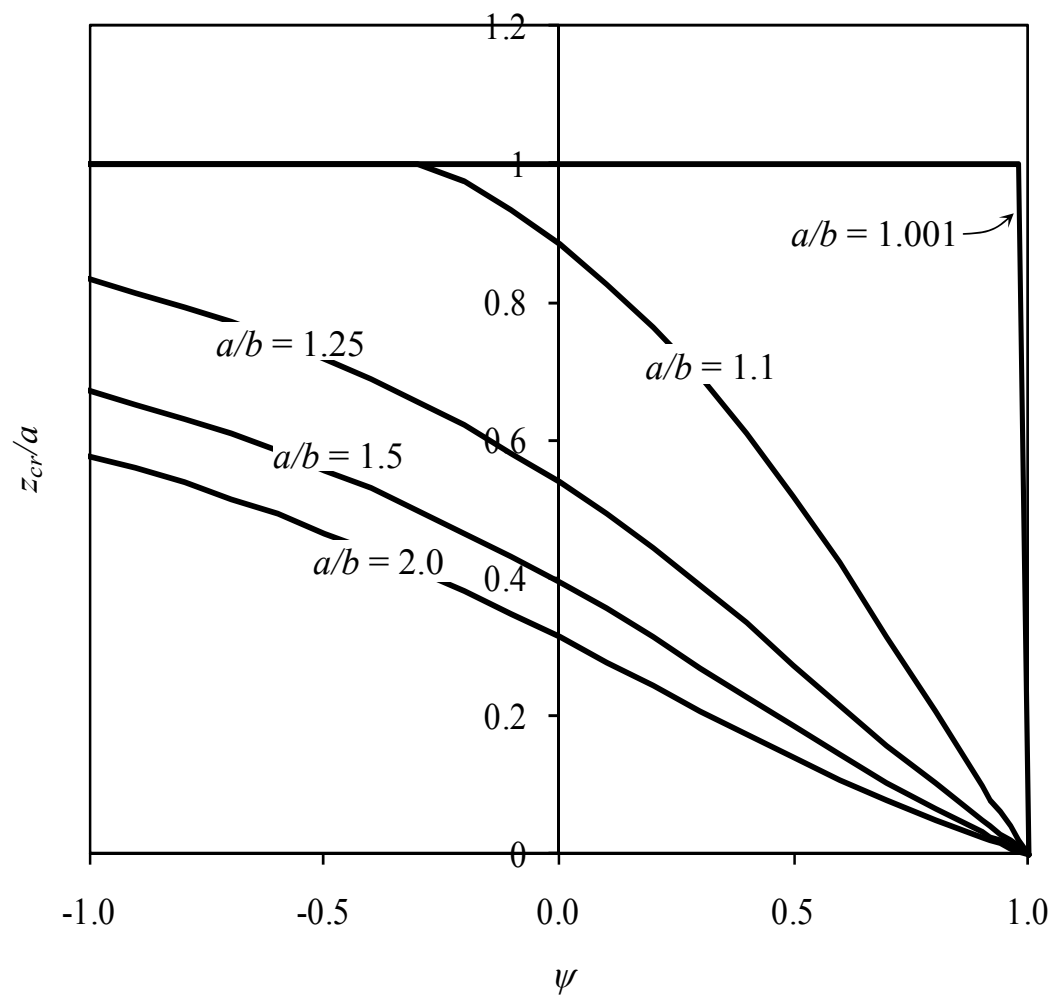

Figure 10. Variation of the Theoretical Position of the

Initiation of Local Buckling with Aspect Ratio $a / b$ and Stress Distribution $\psi$

Eq. 6 is plotted in Figure 11 to show the variation in equivalent diameter $D_{e, m a}$ with the stress ratio $\psi$ for a range of aspect ratios. A linear approximation to the transition in $D_{e, m a}$ with $\psi$ is shown in Figure 11 for $a / b=2.0$ (representing commercially available sections). The linear approximation is given by Eq. 8:

$D_{e, m a}=D_{e, b}+\left(D_{e, c}-D_{e, b}\right)\left(\frac{\psi+1}{2}\right)$

Note that the theoretical end points to Eq. 8, based on approximate elastic buckling arguments, are $D_{e, c}=2 a^{2} / b$ and $D_{e, b}=1.3 a^{2} / b$. However, as presented in Tables 6 and 7 and discussed earlier, these end points have been modified in previous studies based on more rigorous analysis and consideration of observed physical behaviour in tests. For pure compression, Ruiz-Terán and Gardner [7] proposed that $D_{e, c}$ could be taken as:

$D_{e, c}=2 a\left(1+f\left(\frac{a}{b}-1\right)\right), \quad f=1-2.3\left(\frac{t}{2 a}\right)^{0.6}$

though $D_{e, c}=2 a^{2} / b$ could also be conservatively adopted, while for pure bending, Chan and Gardner [4] proposed $D_{e, b}=0.8 a^{2} / b$ for $a / b>1.357$ and $D_{e, b}=2 b^{2} / a$ for $a / b \leq 1.357$. These end points, and a linear transition between them, are compared with equivalent diameters $D_{e, m a}$ obtained from the test and FE results reports herein (for intermediate values of $\psi$ ) and from the literature [3, 4] for pure compression $(\psi=1)$ and pure bending $(\psi=-1)$. The equivalent diameters were determined by comparing elliptical test and FE results with their circular counterparts and then modifying $D_{e}$ until the EHS results were mapped onto the corresponding CHS results. This process is shown schematically in Figure 12, and was carried out, with reference to the interaction expression given in Section 6, for all cases of combined compression plus bending. 


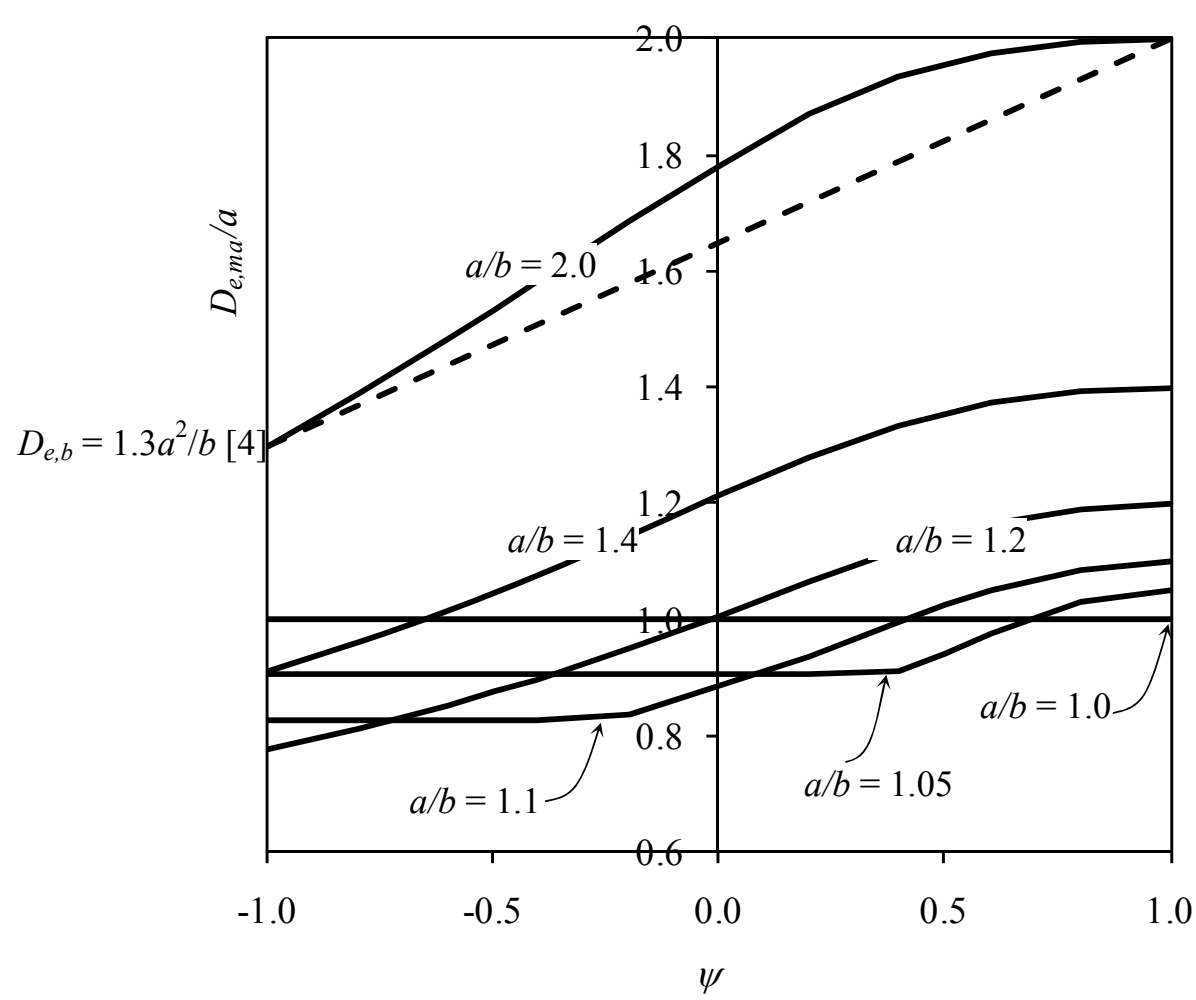

$D_{e, c}=2.0 a^{2} / b[3,28]$

Figure 11. Variation in the Theoretical Equivalent Diameter $D_{e}$ with Stress Ratio $\psi$ and Aspect Ratio $a / b$

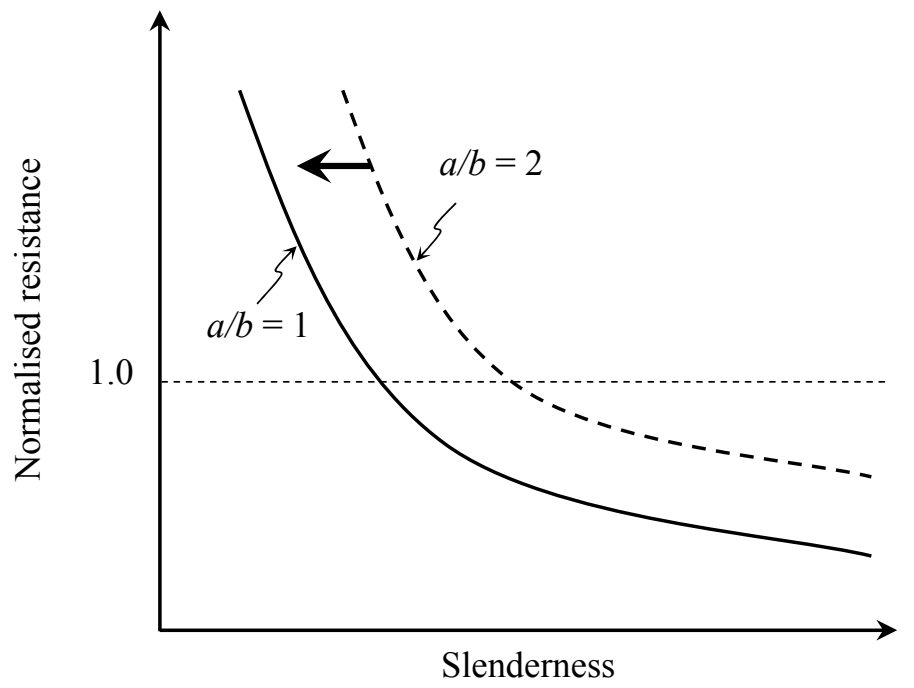

Figure 12. Determination of Equivalent Diameters from Test and FE Results

The obtained equivalent diameters are presented in Figure 13 and compared with the linear transition given by Eq. 8. Note that Figure 13 has two scales on the horizontal axis - the lower one (in terms of $\psi$ ) relates to an elastic stress distribution under combined loading while the upper one (in terms of $\alpha$ ) relates to a plastic stress distribution. The data points corresponding to these two axes were labelled 'elastic' and 'plastic'. For bending, the end point of Eq. 8 is taken as that proposed by Chan and Gardner [4] $-D_{e, b}=0.8 a^{2} / b$, while for compression, the simple $D_{e, c}=2 a^{2} / b$ and the more sophisticated expression of Ruiz-Terán and Gardner [7] are shown, the latter being a function of relative section thickness and is shown for an intermediate value of $t=5.8 \mathrm{~mm}$, which 
is the average section thickness from the parametric studies (with $2 a=150 \mathrm{~mm}$ and $2 b=75 \mathrm{~mm}$ ). The results indicate that the proposed equivalent diameter in bending is appropriate and the simple equivalent diameter in compression $\left(2 a^{2} / b\right)$ is safe but conservative, with more accurate results being obtained from the expression of Ruiz-Terán and Gardner [7]. The linear transition (Eq. 8) may also be seen to be appropriate and may be safely applied with either end point in compression. As described above, the horizontal axis for Figure 13 is also shown in terms of $\alpha$, which relates to the position of the plastic neutral axis and represents the proportion of the cross-section in compression assuming a plastic (rather than an elastic) stress distribution under combined loading. The corresponding data points show that a linear transition in slenderness between $D_{e, c}$ (for $\left.\alpha=1\right)$ and $D_{e, b}$ (for $\alpha=0.5$ ) with $\alpha$, given by Eq. 10 is also appropriate.

$$
D_{e, m a}=D_{e, b}+\left(D_{e, c}-D_{e, b}\right)(2 \alpha-1)
$$

Determination of the positions of both the elastic and plastic neutral axes for EHS under combined loading is discussed in Section 5.

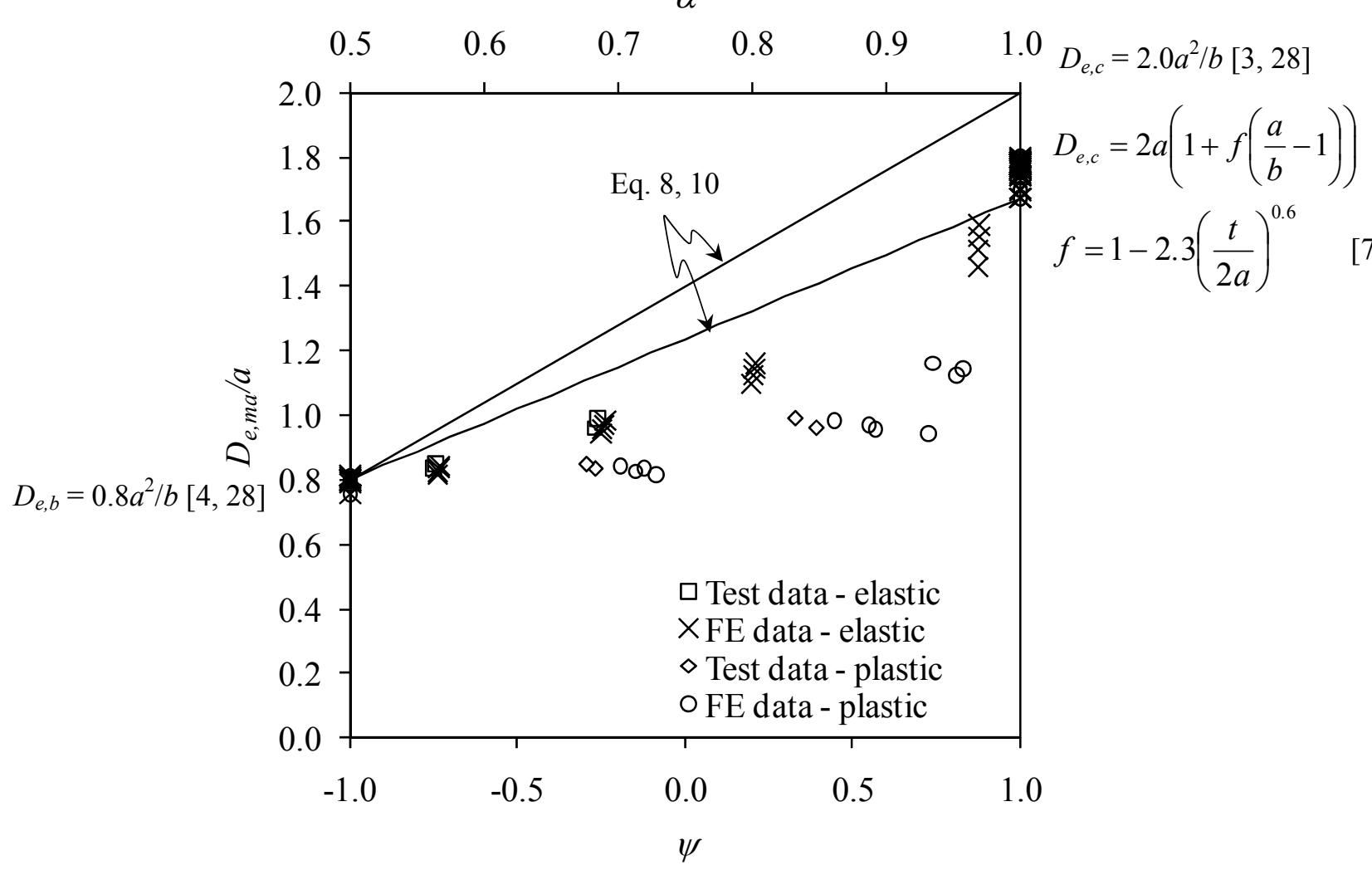

Figure 13. Variation in the Design Equivalent Diameter $D_{e, m a}$ with $\psi$ and $\alpha$ for EHS Cross-sections with $a / b=2.0$

\section{LOCATION OF THE NEUTRAL AXES UNDER COMBINED LOADING}

Location of the position of both the elastic and plastic neutral axes for EHS under combined axial compression and bending is described in this section. The primary focus of this section is on the case of compression plus major axis bending since, under combined compression and minor axis bending the position of the initiation of local buckling (and hence the slenderness parameter) is constant. The described approach may, however, be easily adapted to cover either case. Under combined loading, both the elastic and plastic neutral axes shift relative to their positions under 
bending alone. The particular geometry of an EHS complicates the process of determining this shift, particularly in the case of a plastic stress distribution.

\subsection{Elastic Neutral Axis}

Assuming an elastic stress distribution (i.e. prior to yielding), a cross-section will experience extreme fibre stresses, denoted $\sigma_{1}$ and $\sigma_{2}$, and a linear stress gradient between these points - see Figure 14. The axis of zero stress is termed the elastic neutral axis (ENA).

$$
\text { Compression Compression }
$$

Compression

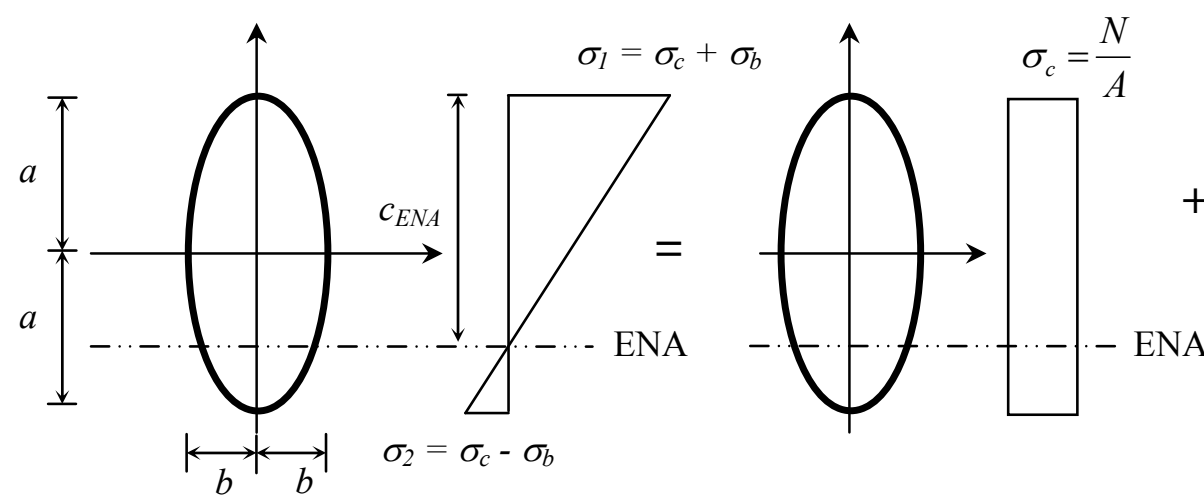

Tension

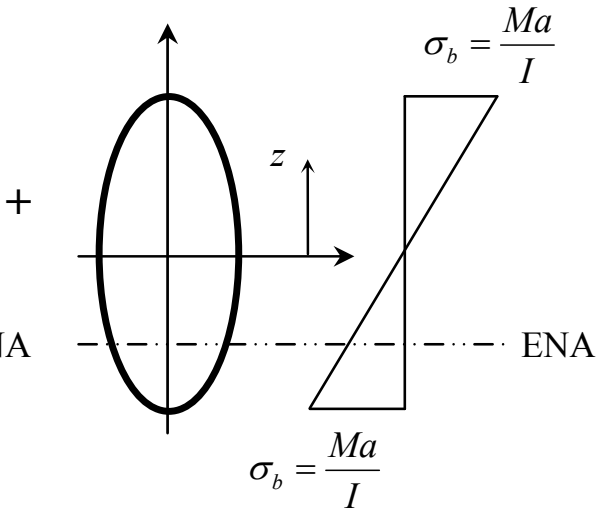

Tension

Figure 14. Elastic Stress Distribution in an EHS under Combined Compression and Major Axis Bending

The distance of the ENA from the top of the cross-section $c_{E N A}$ is given by:

$c_{E N A}=2 a\left(\frac{\sigma_{1}}{\sigma_{1}+\sigma_{2}}\right)=2 a\left(\frac{1}{1+\psi}\right)$

or, in terms of section geometry and applied loading,

$c_{E N A}=a\left(1+\frac{M_{E d}}{N_{E d}} \frac{A a}{I}\right)$

in which $N_{E d}$ is the applied axial compression, $M_{E d}$ is the applied major axis moment, $A$ is the cross-section area and $I$ is the major axis second moment of area. Location of the elastic neutral axis is relevant for Class 3 (and Class 4) cross-sections, whose capacities are determined on the basis of an elastic stress distribution.

\subsection{Plastic Neutral Axis}

An approximate method of locating the plastic neutral axis (PNA) in an EHS under combined compression plus major axis bending is described in this sub-section, with reference to Figure 15.

This area of cross-section in compression may alternatively be expressed as: 
$A_{c}=4 a_{m} t \int_{0}^{\varphi_{h}} \sqrt{\sin ^{2} \varphi+\frac{b_{m}^{2}}{a_{m}^{2}} \cos ^{2} \varphi} d \varphi$

where $a_{m}$ and $b_{m}$ are the half larger and smaller diameters of the ellipse measured to the centreline of the wall thickness (i.e. $a_{m}=a-t / 2$ and $b_{m}=b-t / 2$ ) and $\varphi_{h}$ is defined in Figure 15.

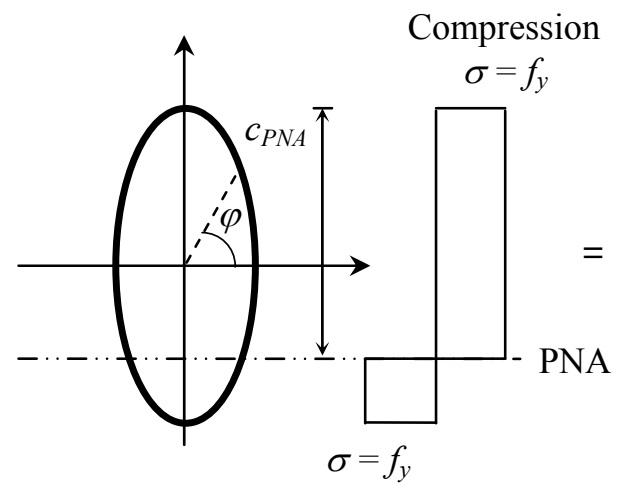

Tension

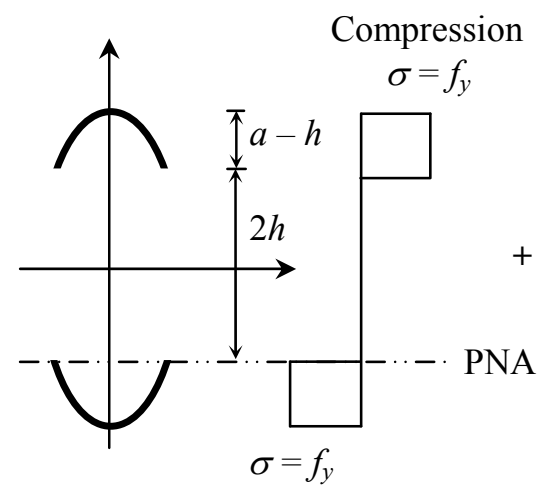

Tension

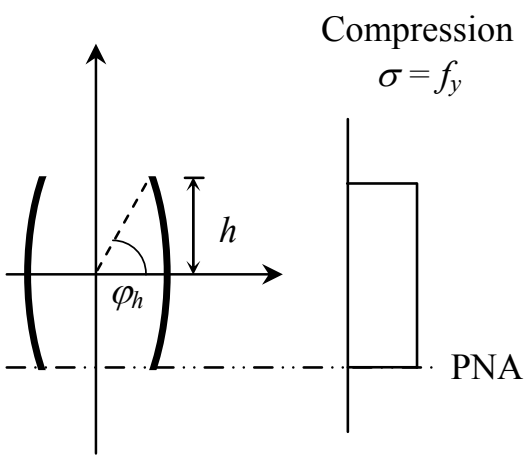

Figure 15. Plastic Stress Distribution in an EHS under

Combined Compression and Major Axis Bending

For an aspect ratio of 2 , the term $\left(b_{m} / a_{m}\right)^{2}$ ranges between 0.23 and 0.25 , depending on the section thickness. Hence, when considering EHS with an aspect ratio $a / b=2$, for simplicity, this term will be taken as constant value of 0.24. Combining Eqs. 13 and 14 therefore leads to:

$\frac{N_{E d}}{4 a_{m} t f_{y}}=\int_{0}^{\varphi_{h}} \sqrt{\sin ^{2} \varphi+0.24 \cos ^{2} \varphi} d \varphi$

The above integral has been evaluated for a range of values of $\varphi$, plotted in Figure 16, for 0 to $\pi / 2$. The resulting normalised relationship between $N_{E d}$ and $\varphi_{h}$ may be approximately represented, for simplicity, by the cubic function given below, which has been added to Figure 16.

$$
\frac{\varphi_{h}}{\pi / 2}=0.25\left(\frac{N_{E d}}{4 a_{m} t f_{y}}\right)^{3}-0.72\left(\frac{N_{E d}}{4 a_{m} t f_{y}}\right)^{2}+1.33\left(\frac{N_{E d}}{4 a_{m} t f_{y}}\right) \quad \text { for } a / b=2
$$

The radius of an ellipse (measure from the centre of the ellipse to its outer perimeter) may be determined at any point from:

$$
r(\varphi)=\frac{a}{1+\left(\frac{a}{b}-1\right) \cos \varphi}
$$


The compressed height $h$ may be calculated from simple geometry as $h=r\left(\varphi_{h}\right) \sin \varphi_{h}$ :

$$
h=\sin \varphi_{h} \frac{a}{1+\left(\frac{a}{b}-1\right) \cos \varphi_{h}}
$$

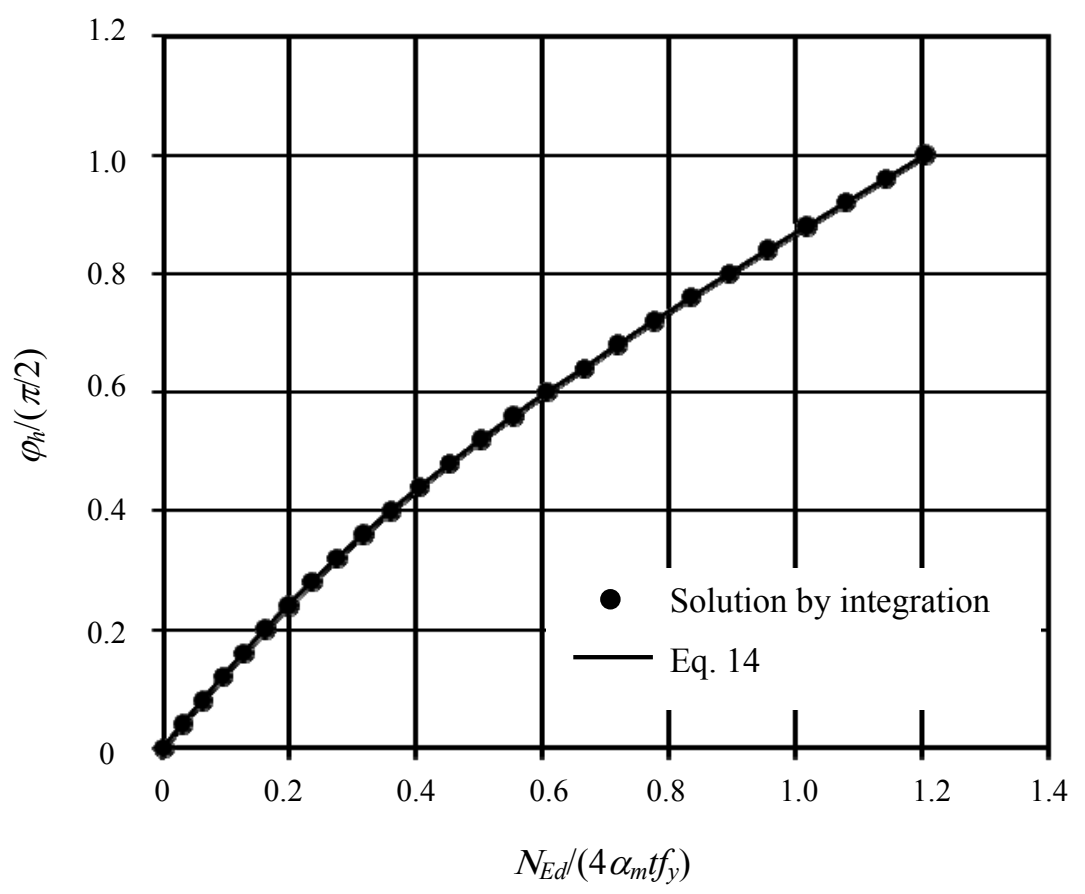

Figure 16. Normalised Relationship between $N$ and $\varphi_{h}$ for $a / b=2$

With reference to Figure 15, the distance from the extreme compressive fibre to the PNA of the cross-section $c_{P N A}$ may be expressed as:

$c_{P N A}=(a-h)+2 h \quad=a+h$

The proportion of the height of the cross-section that is in compression $\alpha_{m a}$ is therefore given by:

$\alpha_{m a}=\frac{c_{P N A}}{2 a}=\frac{1}{2}\left[1+\frac{\sin \varphi_{h}}{1+\left(\frac{a}{b}-1\right) \cos \varphi_{h}}\right]$

where $\varphi_{h}$ may be determined from Eq. 16.

The same procedure may be repeated for compression plus minor axis bending, yielding a compressed proportion of section $\alpha_{m i}$ of: 
$\alpha_{m i}=\frac{c_{P N A}}{2 b}=\frac{1}{2}\left[1+\frac{\cos \varphi_{h}}{1+\left(\frac{b}{a}-1\right) \sin \varphi_{h}}\right]$

\section{SLENDERNESS LIMITS UNDER COMBINED LOADING}

Cross-sections are placed into discrete behavioural classes based upon their susceptibility to local buckling. The limits of these classes provided in BS 5950-1 [23], ANSI/AISC 360-05 [24], AISC [25], AS 4100 [26] and EN 1993-1-1 [27] were presented in Tables 6 and 7 for CHS sections subjected to pure compression and pure bending. The limits proposed for EHS by Chan and Gardner [3,4] and Ruiz-Terán and Gardner [7] are also shown. Classification limits for combined axial compression and bending are addressed in this section.

\subsection{Class 3 Slenderness Limit}

In bending, Class 3 cross-sections are those capable of reaching their elastic moment resistance $M_{e l}$, but local buckling prevents attainment of the plastic moment resistance $M_{p l}$. For Class 4 cross-sections, local buckling occurs prior to yielding and resistance is determined on the basis of an effective cross-section.

Under combined axial compression and bending, Class 3 cross-sections must satisfy:

$$
\frac{N_{E d}}{N_{c, R d}}+\frac{M_{E d}}{M_{e l, R d}} \leq 1.0
$$

where $N_{E d}$ is the applied axial load (taken as the ultimate load $N_{u}$ from the test or FE model), $N_{c, R d}$ is the yield resistance of the cross-section $\left(A f_{y}\right), M_{E d}$ is the applied bending moment about either the major or minor axis (taken as the moment $\left(M_{1+2}=N_{u}\left(e+\delta_{m i d}\right)\right)$ corresponding to $N_{u}$ from the test or FE model) and $M_{e l, R d}$ is the elastic bending resistance ( $W_{e l} f_{y}$, where $W_{e l}$ is the elastic section modulus) about the corresponding axis. The test and FE results for compression plus bending about the minor axis are plotted in Figure 17, while the results for compression plus bending about the major axis are shown in Figure 18. The equivalent diameters under combined loading have been determined, as proposed in Section 4, from Eq. 1 for compression plus minor axis bending and Eq. 8 for compression plus major axis bending. The value of $\psi$ has been calculated for each load eccentricity. The slenderness limits for pure compression $\left(D_{e} / t \varepsilon^{2}=90\right)$ and pure bending $\left(D_{e} / t \varepsilon^{2}=\right.$ 140) have been added to the figures.

A value of $\left(N_{E d} / N_{c, R d}+M_{E d} / M_{e l, R d}\right)$ greater than unity represents meeting of the Class 3 requirement, whilst a value less than unity indicates a Class 4 cross-section. 


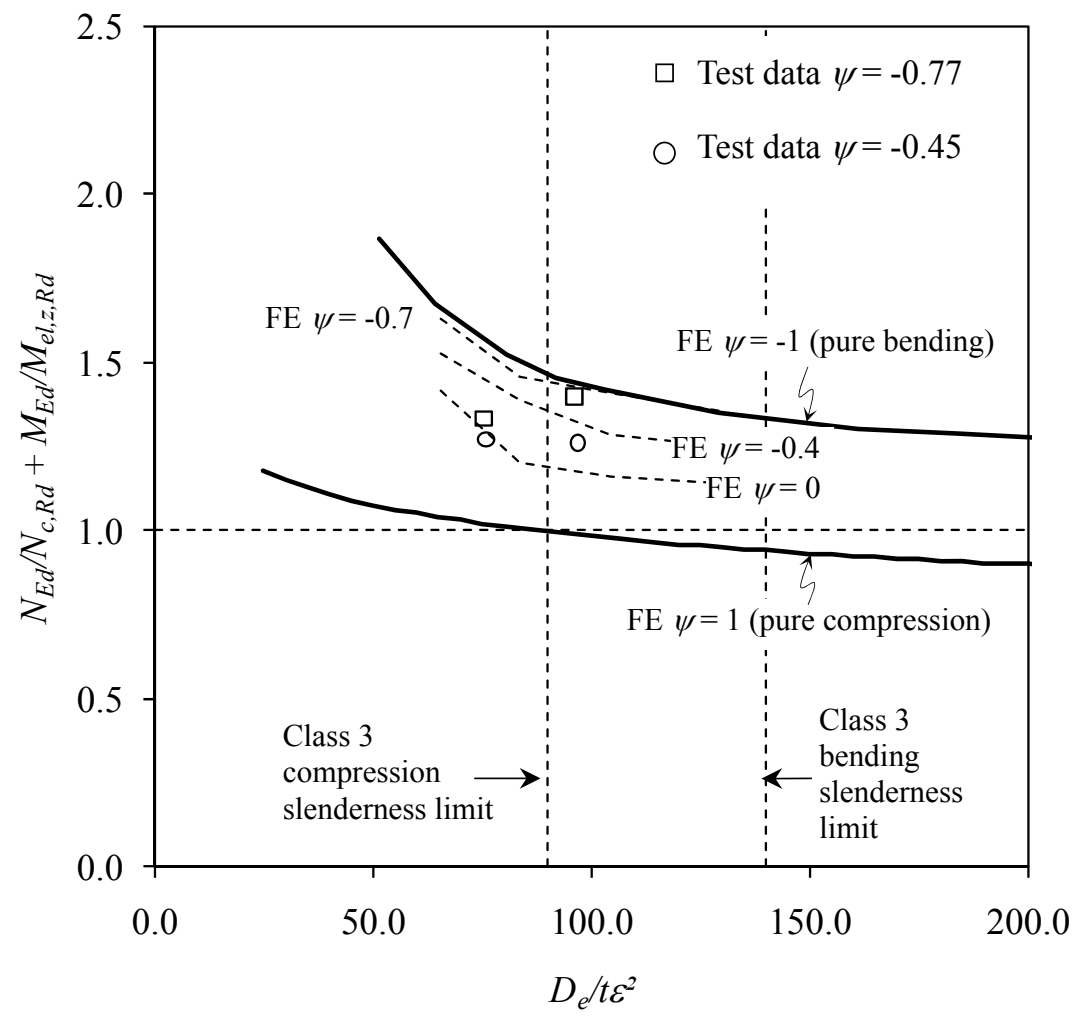

Figure 17. Normalised Resistance under Combined Compression Plus Minor Axis Bending Versus Cross-section Slenderness for EHS with $a / b=2$

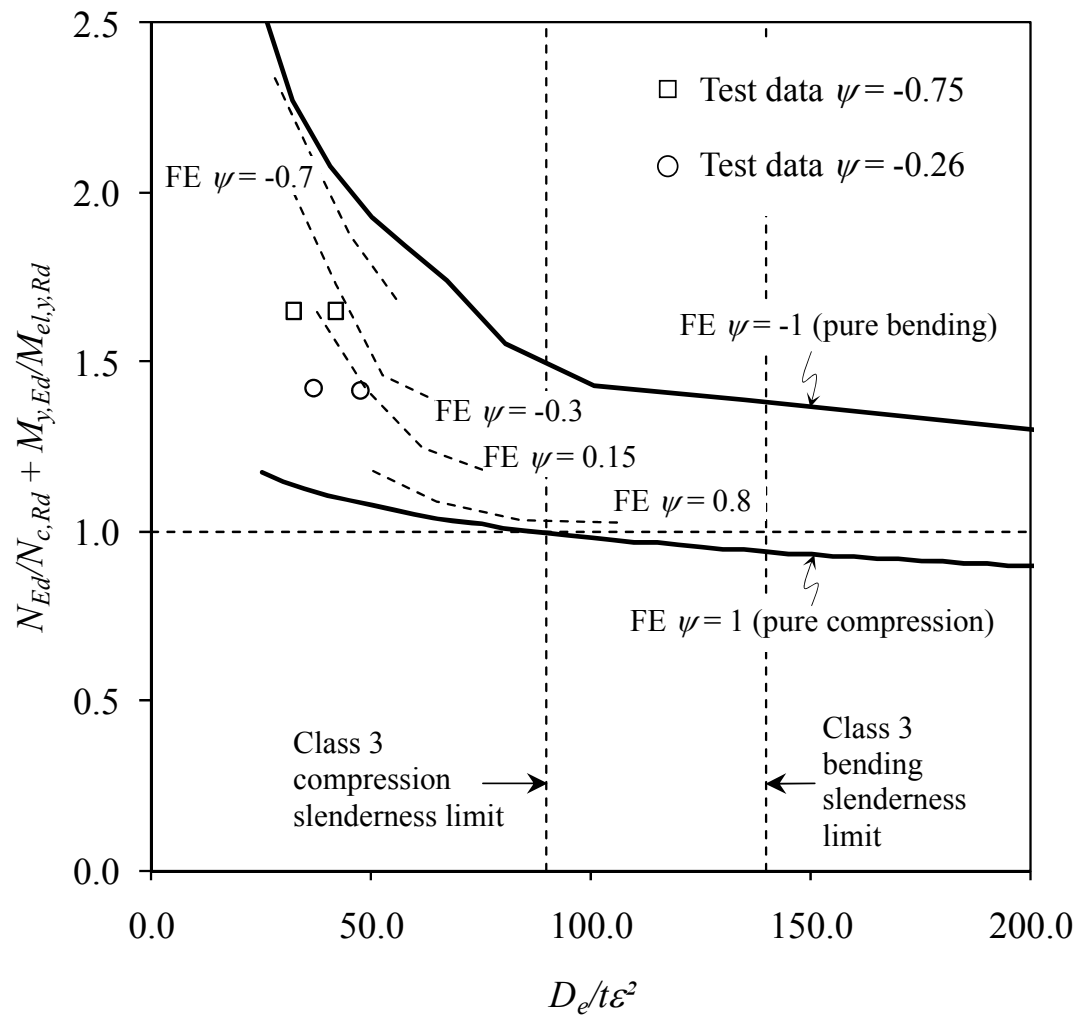

Figure 18. Normalised Resistance under Combined Compression Plus Major Axis Bending Versus Cross-section Slenderness for EHS with $a / b=2$ 
The results from both Figures 17 and 18 indicate a clear transition in structural response as $\psi$ varies from 1 to -1 ; i.e. the normalised resistance $\left(N_{E d} / N_{c, R d}+M_{E d} / M_{e l, R d}\right)$ reduces as the compressed portion of the section, measured through $\psi$ increases. Although not clearly exhibited by the data, the transition in slenderness limit with $\psi$ will be conservatively assumed to be linear (as with other cross-section types in current design standards such as EN 1993-1-1 [27]) leading to:

$$
\frac{D_{e}}{t \varepsilon^{2}}=\frac{2520}{5 \psi+23}
$$

\subsection{Class 1 and 2 Slenderness Limits}

In bending, Class 1 and 2 cross-sections are those capable of reaching their plastic bending moment resistance $M_{p l}$ with the distinction between the two classes made on the basis of rotation capacity. Under combined compression and bending, a cross-section is deemed to be Class 2 (or better) if the fully plastic resistance given by Eq. 24 is exceeded. This expression was derived by Nowzartash and Mohareb [32] and is discussed further in Section 7.2.

$$
2\left(\frac{N_{E d}}{N_{c, R d}}\right)^{1.75}-\left(\frac{N_{E d}}{N_{c, R d}}\right)^{3.5}+\left(\frac{M_{y, E d}}{M_{p l, y, R d}}\right)^{2}+\left(\frac{M_{z, E d}}{M_{p l, z, R d}}\right)^{1.7} \leq 1.0
$$

Figure 19 presents the test and FE results for compression plus major axis bending generated herein on a graph of normalised plastic resistance under combined loading (Eq. 24) versus cross-section slenderness. A value of greater than unity on the vertical axis represents meeting of the requirement for a Class 2 cross-section. For each test and FE model, the compressed proportion of the section $\alpha$ was determined from the loading eccentricity as indicated by Eqs. 20 and 21. In a similar manner to Figures 17 and 18, Figure 19 indicates that there is a transition in slenderness limit with $\alpha$; the higher the value of $\alpha$ (i.e. the greater the proportion of the cross-section in compression), the lower the normalised plastic resistance and the stricter the slenderness limits that is indicated. However, although this transition is apparent, it is proposed to maintain the same Class 2 slenderness limit of $D_{e} / t \varepsilon^{2}=70$ for both compression and bending, and thus, while the slenderness measure varies with $\alpha$ (for compression plus major axis bending), as discussed in Section 4.3, the limit itself does not. This proposal, made for both compression plus major axis bending and compression plus minor axis bending, is in line with the treatment of CHS in EN 1993-1-1 [27]. The same approach is proposed for Class 1 sections, again in line with EN 1993-1-1 [27], with a fixed slenderness limit of $D_{e} / t \varepsilon^{2}=50$. 


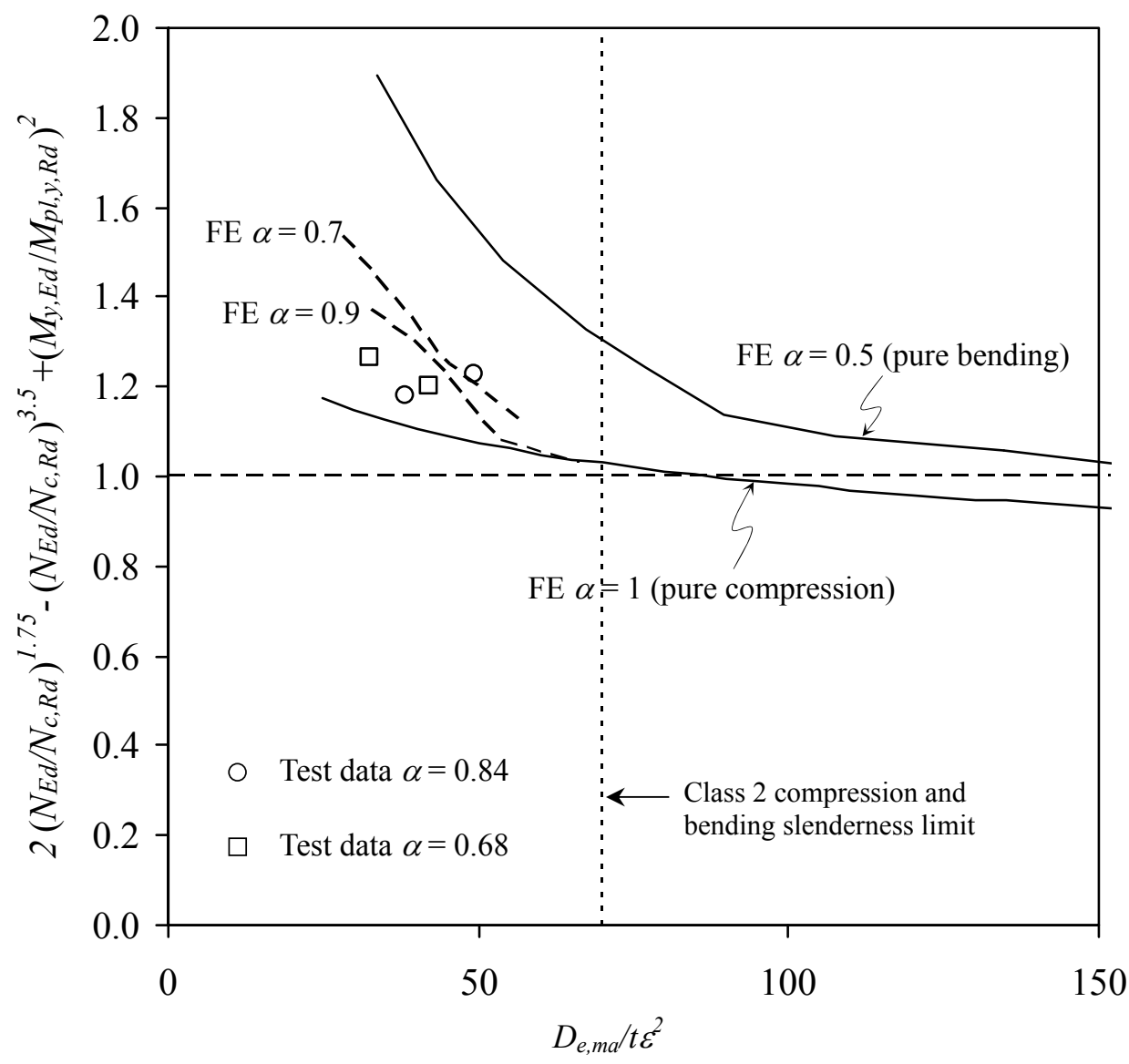

Figure 19. Normalised Plastic Resistance for Combined Compression and Major Axis Bending Versus Cross-section Slenderness for EHS with $a / b=2$

Table 8 summarises the proposed slenderness parameters and classification limits for EHS under combined compression and uniaxial bending determined in Sections 4.3 and 6.1.

Table 8. Summary of Slenderness Parameters and Classification Limits for EHS under Combined Compression and Uniaxial Bending.

\begin{tabular}{c|c|c}
\hline $\begin{array}{c}\text { Cross-section } \\
\text { classification }\end{array}$ & $\begin{array}{c}\text { Proposed } \\
\text { slenderness limits }\end{array}$ & $\begin{array}{c}\text { Cross-section slenderness } \\
\text { Parameter }\end{array}$ \\
\hline Class 1 & $50 \varepsilon^{2}$ & $\begin{array}{c}\text { Compression plus minor }(z-z) \text { axis bending: } \\
D_{e, m i}=\frac{2 a^{2}}{b}\end{array}$ \\
\hline Class 2 & $70 \varepsilon^{2}$ & $\begin{array}{c}\text { Compression plus major }(y-y) \text { axis bending: } \\
D_{e, m a}=D_{e, b}+\left(D_{e, c}-D_{e, b}\right)(2 \alpha-1)\end{array}$ \\
\hline Class 3 & $\frac{2520 \varepsilon^{2}}{5 \psi+23}$ & Compression plus minor $(\mathrm{z}-\mathrm{z})$ axis bending: \\
& & $D_{e, m i}=\frac{2 a^{2}}{b}$ \\
& & Compression plus major $(y-y)$ axis bending: \\
& & $D_{e, m a}=D_{e, b}+\left(D_{e, c}-D_{e, b}\right)\left(\frac{\psi+1}{2}\right)$ \\
\hline
\end{tabular}

$\varepsilon=\left(235 / f_{y}\right)^{0.5}=0.81$ for $f_{y}=355 \mathrm{~N} / \mathrm{mm}^{2}$ 


\section{RESISTANCE UNDER COMBINED LOADING}

Based on the above proposals for cross-section classification, the test and FE results are now compared with their respective interaction expressions to assess their suitability for design.

\subsection{Class 3 and Class 4 Cross-sections}

Current design standards (BS 5950-1:2000 [23], ANSI/AISC 360-05 [24] and EN 1993-1-1:2005 [27]) specify a linear interaction between compression and bending for Class 3 and Class 4 cross-sections. This is also applicable as a conservative treatment for Class 1 and 2 cross-sections. For Class 3 sections, the linear interaction may be expressed as:

$\frac{N_{E d}}{N_{c, R d}}+\frac{M_{y, E d}}{M_{p l, y, R d}}+\frac{M_{z, E d}}{M_{p l, z, R d}} \leq 1.0$

For Class 4 sections, the resistances are calculated on the basis of effective sections properties to allow for the occurrence of local buckling prior to yielding:

$$
\frac{N_{E d}}{N_{c, e f f, R d}}+\frac{M_{y, E d}}{M_{e f f, y, R d}}+\frac{M_{z, E d}}{M_{e f f, z, R d}} \leq 1.0
$$

In these expressions $M_{y, E d}$ and $M_{z, E d}$ are the design bending moments about the major $(y-y)$ and minor $(z-z)$ axes, respectively (where $M_{y, E d}=0$ signifies uniaxial minor axis bending only and $M_{z, E d}$ $=0$ major axis bending only), $M_{e l, y, R d}=W_{e l, y} f_{y}$ and $M_{e l, z, R d}=W_{e l, z} f_{y}$ are the design elastic bending resistance about the major $(y-y)$ and minor $(z-z)$ axes, respectively, $M_{e f f, y, R d}=W_{\text {eff,y }} f_{y}$ and $M_{e f f, z, R d}=$ $W_{\text {eff,z }} f_{y}$ are the elastic bending resistances about the major $(y-y)$ and minor $(z-z)$ axes, respectively, based on effective section properties, $N_{E d}$ is the design axial force and $N_{c, R d}=A f_{y}$ and $N_{\text {eff, } R d}=A_{\text {eff } f y}$ are the design cross-section resistances under uniform compression based on the gross and effective section areas, respectively. Expressions for determining the effective area (Eq. 27) and effective section modulus (Eq. 28) of EHS have been developed (Chan and Gardner [3, 4], based on modification of the corresponding expressions for CHS given in BS 5950-1 [23].

$$
\begin{aligned}
& A_{e f f}=A\left[\frac{90}{D_{e} / t} \frac{235}{f_{y}}\right]^{0.5} \\
& W_{e f f}=W_{e l}\left[\frac{140}{D_{e} / t} \frac{235}{f_{y}}\right]^{0.25}
\end{aligned}
$$

FE results for EHS with Class 3 cross-sections are compared with the linear elastic interaction curve defined by Eq. 25 in Figure 20; none of the test specimens were Class 3 under combined loading. The graph shows that the linear interaction provides a safe prediction of the FE results and is therefore suitable for design purposes. 


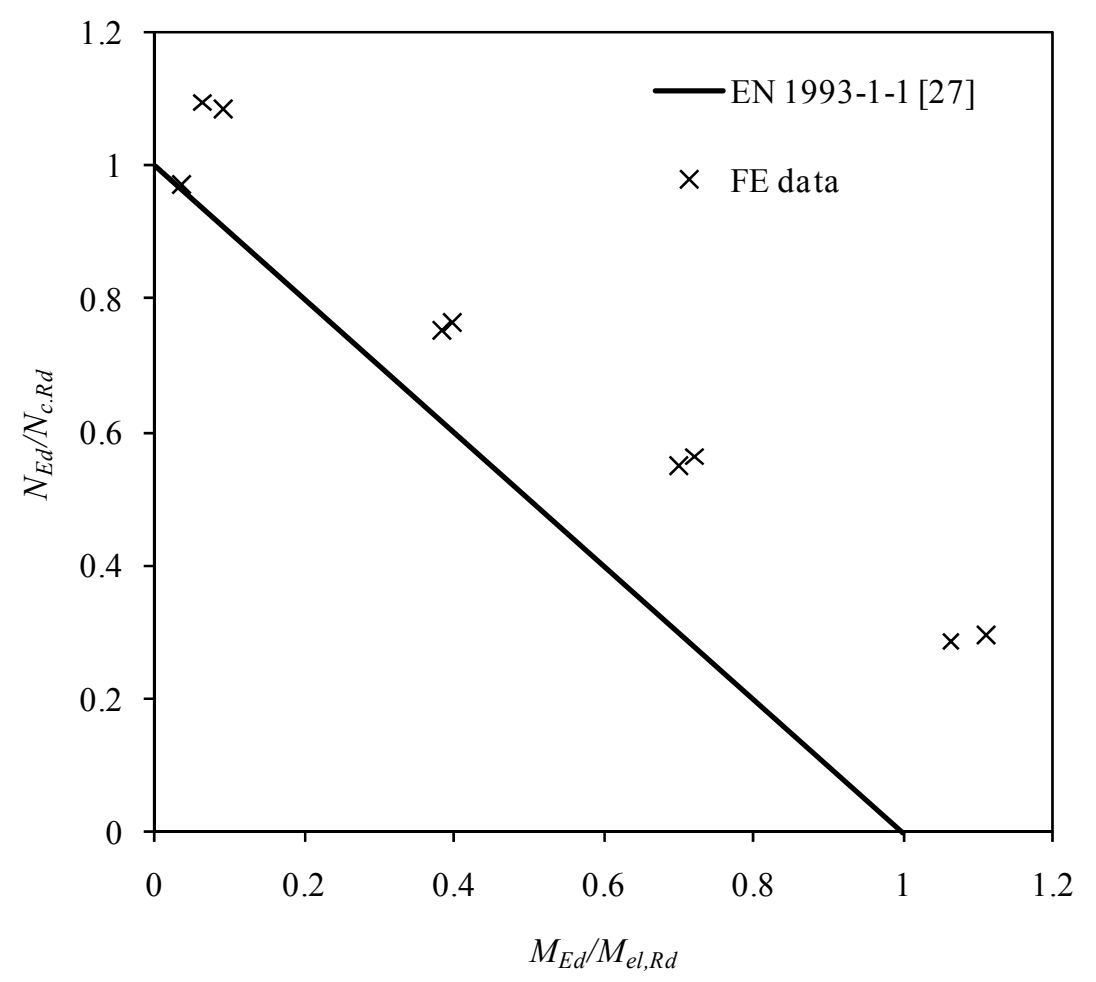

Figure 20. Comparison of Test and FE Results (for Class 3 Cross-sections) with Elastic Interaction Curve for Combined Compression and Bending (about the Major or Minor Axis)

\subsection{Class 1 and Class 2 Cross-sections}

A fully plastic interaction surface for Class 1 and 2 EHS under combined axial compression plus bending has been developed by Nowzartash and Mohareb [32], and is given by Eq. 29.

$2\left(\frac{N_{E d}}{N_{c, R d}}\right)^{1.75}-\left(\frac{N_{E d}}{N_{c, R d}}\right)^{3.5}+\left(\frac{M_{y, E d}}{M_{p l, y, R d}}\right)^{2}+\left(\frac{M_{z, E d}}{M_{p l, z, R d}}\right)^{1.7} \leq 1.0$

where $M_{p l, y, R d}=W_{p l, y} f_{y}$ and $M_{p l, z, R d}=W_{p l, z} f_{y}$ are the design plastic bending resistance about the major and minor axes, respectively.

The results of the test and FE for EHS with Class 1 and 2 cross-sections have been plotted, together with the plastic interaction curve defined by Eq. 29, in Figure 21. The curves may be seen to generally provide safe-side predictions of the test and FE data for both compression plus minor axis bending (Figure 21(a)) and compression plus major axis bending (Figure 21(b), and are therefore recommended for design purposes. It may also be seen that the resistances of the more stocky sections are considerably in excess of the fully plastic resistance, particularly for the case of compression plus major axis bending; this is attributed to the additional capacity resulting from strain hardening. A summary of the resistances of EHS under combined compression and uniaxial bending for all cross-sectional classes is presented in Table 9. 


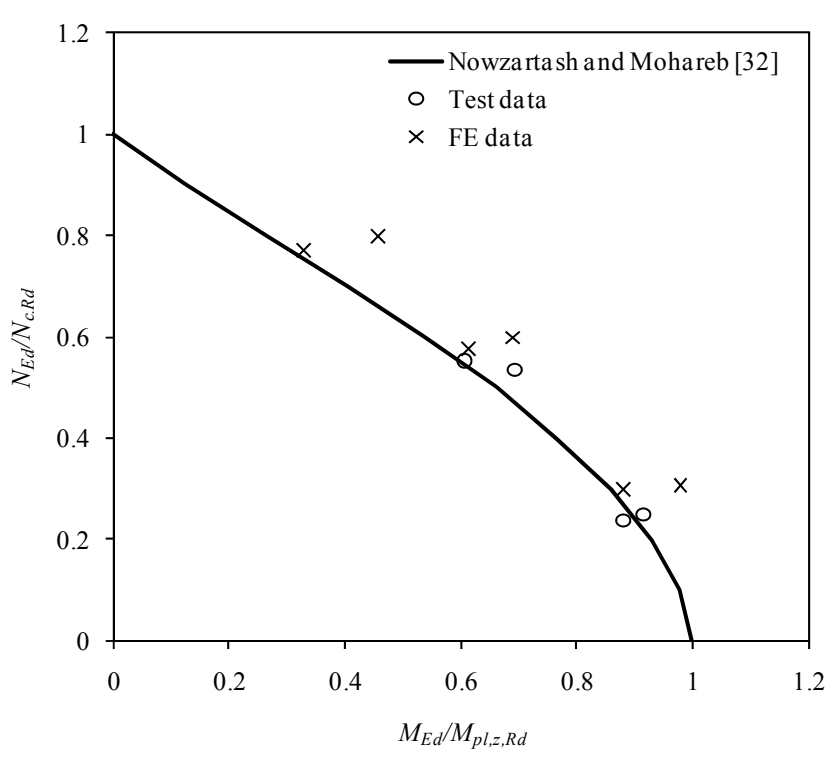

(a) Compression Plus Minor Axis Bending

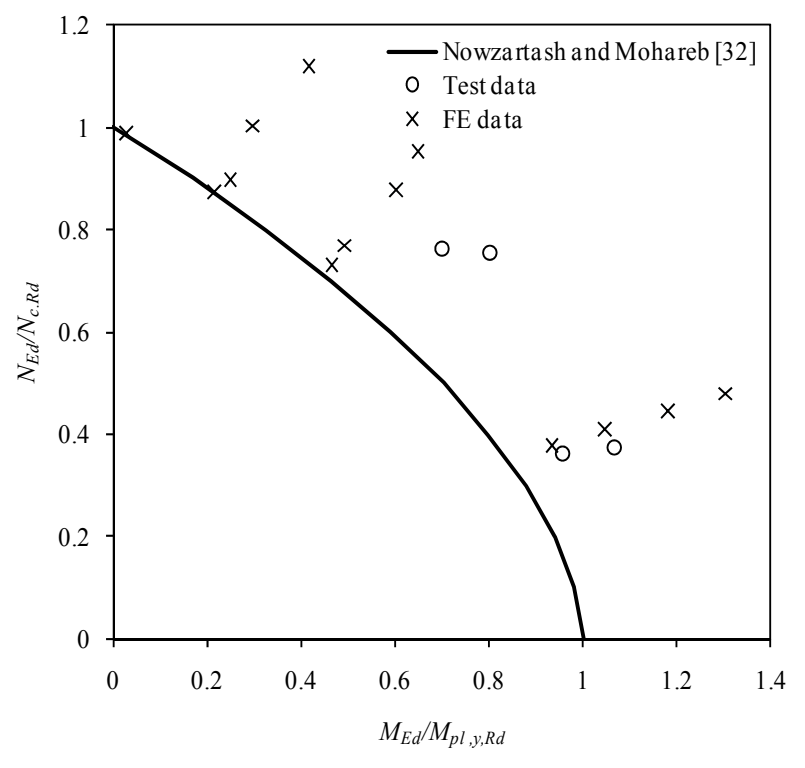

(b) Compression Plus Major Axis Bending

Figure 21. Comparison of Test and FE Results (for Class 1 and 2 Cross-sections) with Plastic Interaction Curves for Combined Compression and Bending

Table 9. Summary of Interaction Formulae for EHS under Combined Compression and Uniaxial Bending

Cross-section classification

Cross-section resistance under combined compression and uniaxial bending

Class 1 and Class 2

$$
2\left(\frac{N_{E d}}{N_{c, R d}}\right)^{1.75}-\left(\frac{N_{E d}}{N_{c, R d}}\right)^{3.5}+\left(\frac{M_{y, E d}}{M_{p l, y, R d}}\right)^{2}+\left(\frac{M_{z, E d}}{M_{p l, z, R d}}\right)^{1.7} \leq 1.0
$$

Class 3

$$
\frac{N_{E d}}{N_{c, R d}}+\frac{M_{y, E d}}{M_{p l, y, R d}}+\frac{M_{z, E d}}{M_{p l, z, R d}} \leq 1.0
$$

Class 4

$$
\frac{N_{E d}}{N_{c, e f f, R d}}+\frac{M_{y, E d}}{M_{e f f, y, R d}}+\frac{M_{z, E d}}{M_{e f f, z, R d}} \leq 1.0
$$

\section{CONCLUSIONS}

The cross-section response of hot-finished elliptical hollow sections (EHS) under combined compression and uniaxial bending has been examined in this study. A total of four tensile coupon tests, four stub columns tests under pure compression and eight under eccentric compression (four about the minor axis and four about the major axis) were performed. Various load eccentricities were considered to vary the proportion of axial load to bending moment. The key material properties, geometric measurements and test results have been reported. Further structural performance data were generated though a parallel finite element study. Equivalent diameters for EHS under compression and uniaxial bending and the corresponding cross-section slenderness limits were derived. On the basis of the experimental and numerical results, fully plastic interaction formulae for Class 1 and 2 cross-sections and an elastic interaction formula for Class 3 
cross-sections were assessed and found to provide safe predictions of the observed physical response. These interaction expressions are therefore recommended for design.

\section{ACKNOWLEDGEMENTS}

The authors would like to thank Corus Tubes for the supply of test specimens, and Colin Banks, Michael Davies and Ryan Griffith (University of Warwick) for their assistance with the experiments, and Dimitrios Moutaftsis for his contribution to the paper.

\section{REFERENCES}

[1] Corus, "Celsius ${ }^{\circledR} 355$ Ovals", Corus Tubes - Structural \& Conveyance Business, 2006.

[2] Viñuela-Rueda, L. and Martinez-Salcedo, J., "Steel Structure and Prestressed Façade of the New Terminal Building”, Hormigon Acero, 2006, Vol. 239, No. 1, pp. 71-84.

[3] Chan, T.M. and Gardner, L., "Compressive Resistance of Hot-rolled Elliptical Hollow Sections", Engineering Structures, 2008, Vol. 30, No. 2, pp. 522-532.

[4] Chan, T.M. and Gardner, L., "Bending Strength of Hot-rolled Elliptical Hollow Sections", Journal of Constructional Steel Research, 2008, Vol. 64, No. 9, pp. 971-986.

[5] Gardner L. and Chan T. M., "Cross-section Classification of Elliptical Hollow Sections", Steel and Composite Structures, 2007, Vol. 7, No. 3, pp. 185-200.

[6] Zhu, Y. and Wilkinson, T., "Finite Element Analysis of Structural Steel Elliptical Hollow Sections in Pure Compression", Proceedings of the 11th International Symposium on Tubular Structures, Québec City, Canada, 2006, pp. 179-186.

[7] Ruiz-Terán, A.M. and Gardner, L., "Elastic Buckling of Elliptical Tubes", Thin-Walled Structures, 2008, Vol. 46, No. 11, pp. 1304-1318.

[8] Silvestre, N., "Buckling Behaviour of Elliptical Cylindrical Shells and Tubes under Compression", International Journal of Solids and Structures, 2008, Vol. 45, No. 16, pp.4427-4447.

[9] Roufegarinejad, A. and Bradford, M.A., "Local Buckling of Thin-walled Elliptical Tubes Containing an Elastic Infill", Proceedings of the 3rd International Conference on Steel and Composite Structures, Manchester, United Kingdom, 2007, pp. 943-948.

[10] Zhao, X.L., Lu, H. and Galteri, S., "Tests of Elliptical Hollow Sections Filled with SCC (Self-Compacting Concrete)", Proceedings of the 5th International Conference on Advances in Steel Structures, Singapore, 2007, pp. 950-955.

[11] Yang, H., Lam, D. and Gardner, L., "Testing and Analysis of Concrete-filled Elliptical Hollow Sections", Engineering Structures, 2008, Vol. 30, No. 12, pp. 3771-3781.

[12] Zhao, X.L. and Packer, J.A., "Tests and Design of Concrete-filled Elliptical Hollow Section Stub Columns", Thin-Walled Structures, 2009, Vol. 47, No. 6-7, pp. 617-628.

[13] Bortolotti, E., Jaspart, J.P., Pietrapertosa, C., Nicaud, G., Petitjean, P.D. and Grimault, J.P., "Testing and Modelling of Welded Joints between Elliptical Hollow Sections", Proceedings of the 10th International Symposium on Tubular Structures, Madrid, Spain, 2003, pp. 259-266.

[14] Choo, Y.S., Liang, J.X. and Lim, L.V., "Static Strength of Elliptical Hollow Section X-joint under Brace Compression", Proceedings of the 10th International Symposium on Tubular Structures, Madrid, Spain, 2003, pp. 253-258.

[15] Pietrapertosa, C. and Jaspart, J.P., "Study of the Behaviour of Welded Joints Composed of Elliptical Hollow Sections", Proceedings of the 10th International Symposium on Tubular Structures, Madrid, Spain, 2003, pp. 601-608. 
[16] Willibald, S., Packer, J.A. and Martinez-Saucedo, G., "Behaviour of Gusset Plate Connections to Ends of Round and Elliptical Hollow Structural Section Members", Canadian Journal of Civil Engineering, 2006, Vol. 33, No. 4, pp. 373-383.

[17] Corus, "Celsius ${ }^{\circledR} 355$ Ovals - Sizes and Resistances Eurocode Version", Corus Tubes Structural \& Conveyance Business, 2006.

[18] European Committee for Standardization (CEN), "Metallic Materials - Tensile Testing - Part 1: Method of Test at Ambient Temperature", EN 10002-1, 2001.

[19] Rasmussen, K.J.R., "Compression Tests of Stainless Steel Tubular Columns", Investigation Report S770, Centre for Advanced Structural Engineering, University of Sydney, 1990.

[20] Gardner, L. and Nethercot, D.A., "Experiments on Stainless Steel Hollow Sections - Part 1: Material and Cross-sectional Behaviour", Journal of Constructional Steel Research, 2004, Vol. 60, No. 9, pp. 1291-1318.

[21] Fujimoto, T., Mukai, A., Nishiyama, I. and Sakino, K., "Behavior of Eccentrically Loaded Concrete-filled Steel Tubular Columns", Journal of Structural Engineering, ASCE, 2004, Vol. 130, No. 2, pp. 203-212.

[22] ABAQUS. ABAQUS, Version 6.9-1, Pawtucket (USA): Hibbit, Karlsson \& Sorensen, Inc.; 2009.

[23] British Standard, "Structural Use of Steelwork in Building, Part1: Code of Practice for Design - Rolled and Welded Sections", BS 5950-1, BSI, 2000.

[24] American Institute of Steel Construction, Inc. (AISC), "Specification for Structural Steel Buildings", ANSI/AISC 360-05, 2005.

[25] American Institute of Steel Construction, Inc. (AISC), "Load and Resistance Factor Design Specification for Steel Hollow Structural Sections", AISC, 2000.

[26] Australian Standard, "Steel Structures", Standards Australia, Homebush, New South Wales, Australia, AS 4100, 1998.

[27] European Committee for Standardization (CEN), "Eurocode 3: Design of Steel Structures Part 1-1: General Rules and Rules for Buildings", EN 1993-1-1, 2005.

[28] Kempner, J., "Some Results on Buckling and Postbuckling of Cylindrical Shells", Collected Papers on Instability of Shell Structures, NASA TND-1510, 1962, pp. 173-186.

[29] Hutchinson, J.W., "Buckling and Initial Postbuckling Behaviour of Oval Cylindrical Shells under Axial Compression”, Journal of Applied Mechanics, 1968, Vol. 35, No. 1, pp. 66-72.

[30] Gerard, G. and Becker, H., "Handbook of Structural Stability: Part III - Buckling of Curved Plates and Shells", NACA Technical Note 3783, 1957.

[31] SCI/BSCA, "Steel Building Design: Design Data in Accordance with Eurocodes and the UK National Annexes", The Steel Construction Institute and British Constructional Steelwork Association, SCI Publication, 2008, pp. 363.

[32] Nowzartash, F. and Mohareb, M., "Plastic Interaction Relations for Elliptical Hollow Sections", Thin-Walled Structures, 2009, Vol. 47, No. 6-7, pp. 681-691. 